\begin{tabular}{|l|l|r|}
\hline $\begin{array}{l}\text { 2. To: (Receiving Organization) } \\
\text { Distribution }\end{array}$ & $\begin{array}{l}\text { 3. From: (Originating Organization) } \\
\text { Retrieval Engineering 73530 }\end{array}$ & $\begin{array}{l}\text { 4. Related EDT No.: } \\
\text { N/A }\end{array}$ \\
\hline $\begin{array}{l}\text { 5. Proj./Prog./Dept./Div.: } \\
\text { Waste Management }\end{array}$ & $\begin{array}{l}\text { 6. Cog. Engr.: } \\
\text { D. C. Ramsower }\end{array}$ & $\begin{array}{l}\text { 7. Purchase Order No.: } \\
\text { N/A }\end{array}$ \\
\hline
\end{tabular}

8. Originator Remarks:

This document is being processed for release.

9. Equip./Component No.:

$$
\text { N/A }
$$

10. Systen/Bldg./Facility:

$$
\text { N/A }
$$

11. Receiver Remarks:

12. Major Assm. OWg. Mo.:

$N / A$

13. Permit/Permit Application No.: N/A

14. Required Response Date:

$$
N / A
$$

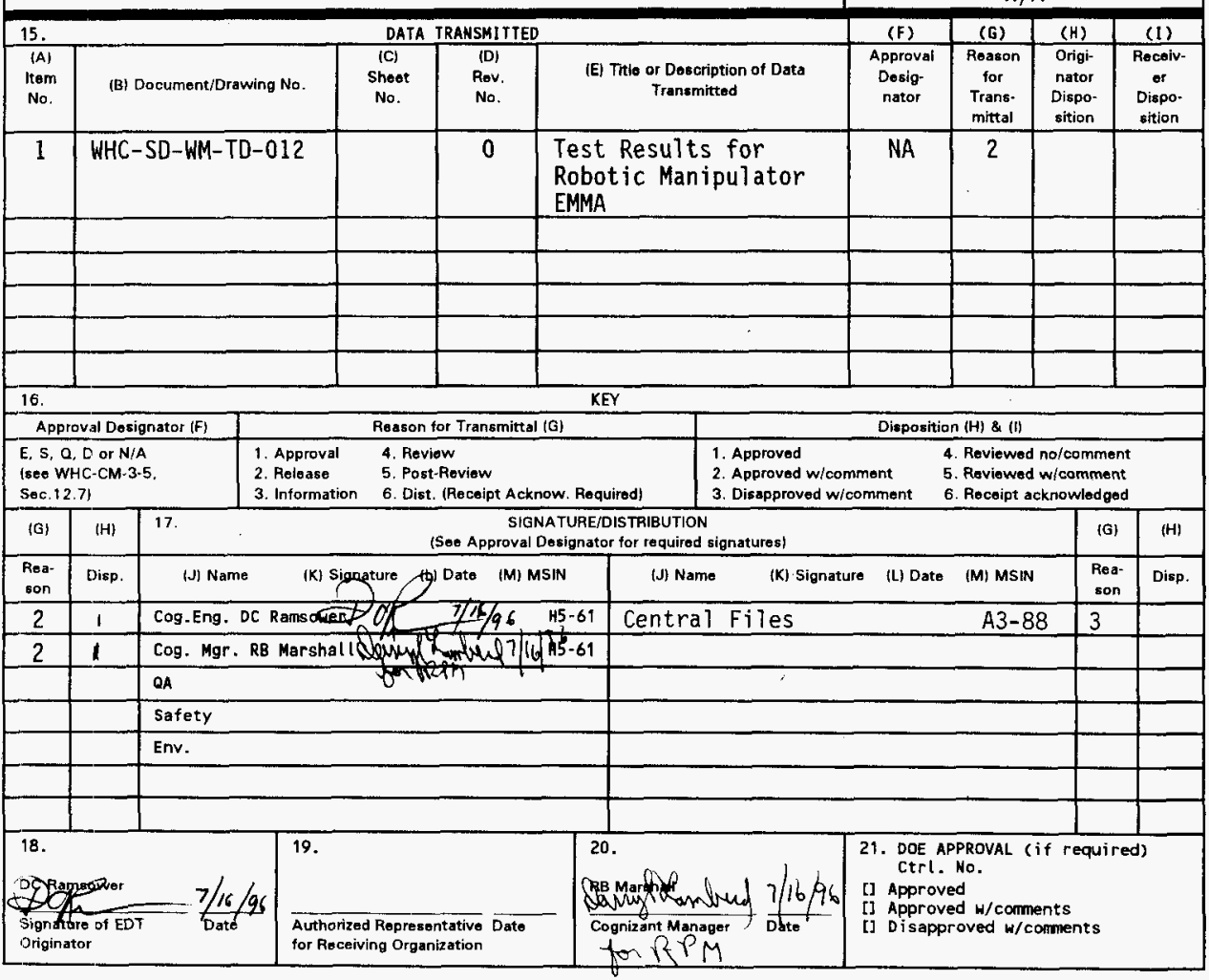

BD-7400-1/2-2(04/94) GEF097 
WHC-SD-WM-TD-012, Rev. 0

\title{
Test Results for Robotic Manipulator EMMA
}

\author{
D. C. Ramsower
}

Westinghouse Hanford Company, Richland, WA 99352

U.S. Department of Energy Contract DE-AC06-87RL10930

$\begin{array}{llll}\text { EDT/ECN: } & 605664 & \text { UC: } & 2000 \\ \text { Org Code: } & 73530 & \text { Charge Code: } & \text { D2027 } \\ \text { B\&R Code: } & \text { EW3130010 } & \text { Total Pages: } & 53\end{array}$

Key Words: robotic manipulator, GreyPilgrim, EMMA, ACTR testing

Abstract: Testing was performed at the National Institute of Standards and Technology (NIST) headquarters in Gaithersburg, Maryland, where GreyPilgrim has experimental space available under a Cooperative R\&D Agreement (CRADA) with NIST. Under the CRADA, GreyPilgrim is tasked with developing a version of EMMA suitable for deployment of a stereo camera on a NIST Robocrane, a mobile platform with applications to several industrial environments (including hazardous materials) based on the concept of the Steward Platform, a structure with great strength and a minimum of material.

TRADEMARK DISCLAIMER. Reference here in to any specific comercial product, process, or service by trade name, trademark, manufacturer, or otherwise, does not necessarily constitute or imply its endorsement, recommendation, or favoring by the United States Government or any agency thereof or its contractors or subcontractors.

Printed in the United States of America. To obtain copies of this document, contact: WHC/BCS Dochment Control Services, P.O. Box 1970, Mailstop H6-08, Richland WA 99352, Phone (509) 372-2420; Fax (509) 376-4989.
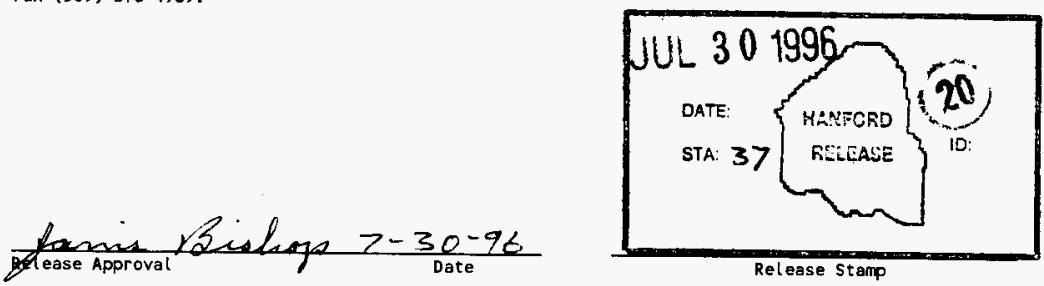

\section{Approved for Public Release}


WHC-SD-WM-TD-012, $\operatorname{Rev} 0$

Test Results for Robotic Manipulator EMMA

July 1996

David C. Ramsower

Prepared by:

GreyPilgrim LLC Gaithersburg, Maryland

for:

Westinghouse Hanford Company

Richland, Washington 


\title{
TEST RESULTS FOR
}

\section{ROBOTIC MANIPULATOR EMMA}

\author{
Testing performed by Greypilgrim LLC \\ under contract to Westinghouse Hanford Corporation \\ and at the National Institute for Standards and Technology \\ Gaithersburg, Maryland \\ March, 1996 \\ Dr. Ronald E. Graham \\ Project Engineer for Robotics \\ GreyPilgrim LIC \\ April 22, 1996
}




\section{TABLE OF CONTENTS}

SECTION

PAGE

INTRODUCTION. .............................

TEST SETUP............................... 4

1.0 Payload Accomodation...................... 6

2.0 Static Cable Tension Determination and Scale-up........ .7

3.0 Dynamic Cable Tension Requirements and Scale-up........ 11

4.0 Kinematics and Control..................... 16

5.0 Pretension and stability ................... 19 APPENDICES

A scale-up numbers from static test................ 21

B Static test results........................ 24

C Dynamic test results...................... 32

D Original statement of work.................. 50

\section{IIST OF FIGURES}

1. Clamps provide rigidity to support structure......... 5

2. Example of Stage One Tension and Coupling Effort....... 9

3. Orientations for two Dynamic Test Runs.............. 14

4. Dynamic Test Measurement Apparatus................ 15

5. Prototype of Joystick used for Testing............. 17

6. Updated Joystick/Load Cells Control Hardware........... 18

7. Conduit and winches on EMMA-A................ 20 
WHC-SD-HM-TD-012, Rev 0

\section{TEST SETUP}

Testing was performed at the National Institute of Standards and Technology (NIST) headquarters in Gaithersburg, MD, where GreyPilgrim has experimental space available under a Cooperative R\&D Agreement (CRADA) with NIST. Under the CRADA, GreyPilgrim is tasked with developing a version of EMMA suitable for deployment of a stereo camera on a NIST Robocrane, a mobile platform with applications to several industrial environments (including hazardous materials) based on the concept of the stewart Platform, a structure with great strength and a minimum of material.

Although the versions of EMMA intended for NIST and for WHC are different in size and scope, the basic design is the same for each -- and thus the results of testing are applicable for both. Besides access to laboratory and shop facilities, NIST has made available expertise to Greypilgrim, particularly in areas in which NIST has considerable experience, such as the development of cable-driven mechanisms and control system/user interfaces (e.g joysticks).

At NIST currently are two prototypes of EMMA: the first, referred to as EMMA-A, is about eight feet in length and has six electric winches mounted, each of those having a rated pull in the 1000 lbf range. EMMA-A has two stages, and the electric winches are connected to stage one. Hand winches are mounted for stage two -six more electric winches are available but were not mounted for this round of tests. The cables used on EMMA-A were 1/8" aircraft cable, which was sized to be suitable for the electric winches. EMMA-A was used for the completion of tests 4.0 and 5.0 .

The second prototype, referred to as EMMA-B, is the root from which the NIST CRADA is expected to be fulfilled. EMMA-B is also about eight feet in length, and has twelve hand winches mounted, each of those having a rated pull of about $2000 \mathrm{lbf}$. The larger pull was considered necessary for the completion of tests 2.0 and 3.0 - although some of test 5.0 was performed with EMMA-B as well. The cables used on EMMA-B were 3/16" aircraft cable, which has a breaking tension load of $4200 \mathrm{lbf}$. Such a load is beyond the rated capacity of all the winches used, but if a single cable even bears half this breaking load, it's still beyond the capability of the available electric winches. For this reason, tests 2.0 and 3.0 were completed with hand winches.

EMMA-B was mounted in a pit in the test cell, with clamps to secure its wooden support structure in place, as shown in Figure 1. This was necessary to prevent the support structure from responding to vibration inputs in the tests under section 3.0 . 
WHC-SD-WM-TD-012, Rev 0

Figure 1. EMMA-B featuring Support Structure and Dynamic setup.

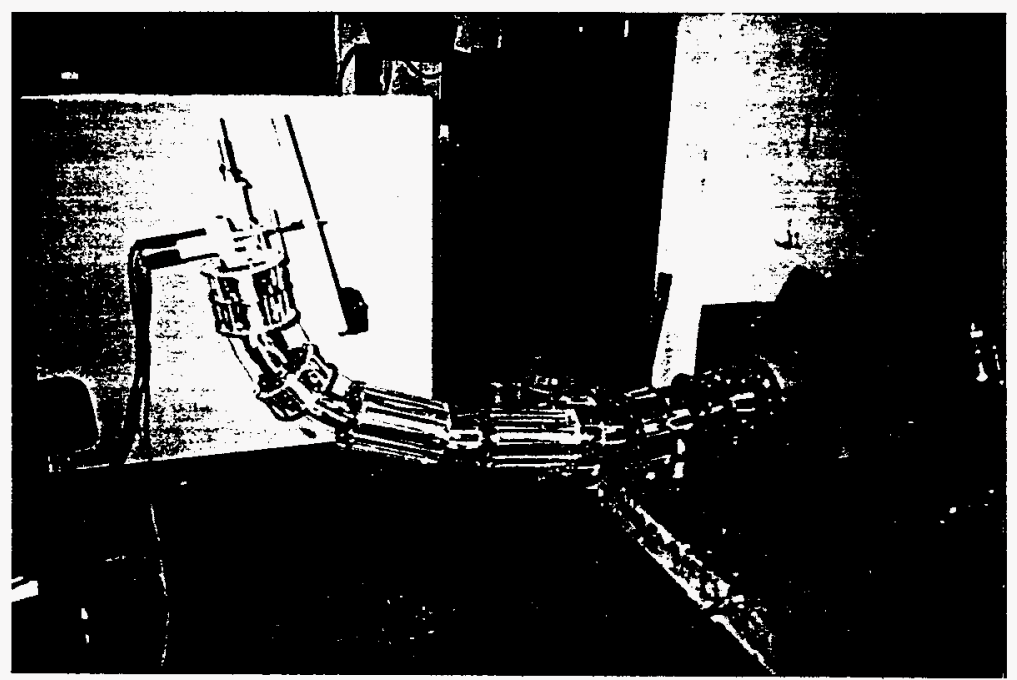

BEST AVAILABLE COPY 


\subsection{Payload Accommodation}

\section{Preparation}

Observations taken in tests under other sections (particularly sections 2.0 and 3.0 ) will enable us to determine the ability of a 30-foot EMMA to accommodate the expected waste-dislodging end-effector. In particular, what we are interested in is the separation between EMMA and end-effector resonance frequencies, and in the effect of the end-effector static load on cable tension. Testing in section 4.0 will result in an estimate of winch rate resolution -- something we can use to determine stand-off capability.

What we know about potential end-effectors to date can be summarized in communications from WHC concerning the Combined Sluicing End-Effector (CSEE). The CSEE operates at $100 \mathrm{~Hz}$, causing an equivalent load at that frequency of magnitude $70 \mathrm{lbf}$.

\section{Conclusions}

Testing under section 2.0 showed us that EMMA could position a static load of 60 lbf, supported by a single cable, with repeatability of less than 0.5 inches based solely on stage two motion through 120 degrees of rotation; and based on stage one motion through 90 degrees with even better repeatability.

Testing under section 3.0 revealed an EMMA resonant frequency close to $3.5 \mathrm{~Hz}$; that that frequency changes relatively little as EMMA's orientation is changed; that excitation at frequencies of 1 $\mathrm{Hz}$ or less will not result in large vibration amplitudes unless the excitation is provided by a force much larger than expected from the CSEE; and that EMMA orientations with large vibration amplitudes tend also to large damping ratios.

At higher frequencies, such as those expected from the CSEE, the smaller amplitudes of vibration that can be expected should have minimal impact on end-effector pointing accuracy. Even if a cable should fail as a result of CSEE cycling, EMMA can accommodate the failure with small loss in accuracy and repeatability.

Testing under section 4.0 resulted in a joystick design which, with some few modifications, can for WHC's application can be made to control cable travel rate to an almost arbitrarily small

(within the capability of the winches) accuracy. Controlling to small rates means that tight stand-off accuracy can be achieved.

The fact that EMMA is hollow throughout its length makes payload accommodation simple in terms of deployment and conveyance. 


\subsection{Static Cable Tension Determination and Scale-up}

Stage One Preparation

This series of tests will be performed with a scale dynamometer mounted alternately on the 12-o'clock stage one and 12-0'clock stage two segment cables. These cables can be assumed for purposes of this test to undergo the largest static loads -- though the tests will be designed to ensure that these cables will be in full tension even though others may be relaxed. In the place of an end-effector will be a static load of 0, 30, or $60 \mathrm{lbf}$.

Two position cases will be considered:

- Case \#1: stage one locked in horizontal position; stage two rotated 90 degrees to vertical

- Case \#2: stage one rotated 90 degrees to vertical; stage two in-line

These position cases are probably the worst cases that will be faced by a two-stage EMMA. (It is unfortunate that the numbering of cases and that of stages are reversed.)

While these position cases can be arguably the worst an EMMA will face, they were not sufficient for the completion of this test. We thought more data points were needed to guide scale-up efforts. The two cases above instead served as end-points for the static test actually performed -- with the exception that for Case \#1, stage two was rotated through 120 degrees.

For Case \#2 (the test of stage one), stage two was held in tension by six cables, each run through conduit through stage one to ensure their decoupling from stage one motion (and this behavior was checked periodically, and qualitatively, in keeping with requirements of section 5.0 ). Stage one was supported by a single cable, at 12 o'clock.

A board was set up alongside EMMA. On this board was indicated each ten degrees of rotation from 0 through 90 : this was done with a laser pointer mounted at the end-effector location and pointed toward the board. Using the pointer's beam as the center, a oneinch diameter circle was marked on the board. These circles represented targets for repeatability: if the beam was inside the circle, pointing error was less than one degree. (More often than not, the beam hit a bulls-eye.) 
As the testing progressed, we noticed stage one would actually sag a few degrees near the origin, for large static loads -- but stage two could still hit the target if stage one was adjusted to compensate. This phenomenon convinced us to "randomize" the order of the static loads introduced $(0,30,60,30,60,0,60,0,30)$ during nine runs of this test, thus overcoming this and any other time-related effect on the resulting data.

The test will be performed as follows:

- rotate stage one through ten-degree increments from neutral to final position, using only the 12 o'clock cable

- measure tension in target cable immediately

- allow coupling to reach final load

- measure tension in target cable again

The data taken in this test enables us to predict cable tension under various conditions (and for various sizes of EMMAs); and to predict pointing accuracy with some confidence.

Stage One Conclusions

- As static load increases, the angle at which cable tension is maximized decreases -- but it took a substantial load (e.g. more than $30 \mathrm{lbf}$ ) to decrease that angle appreciably from 90 degrees.

- The maximum cable tension encountered during this portion of the test was under 1700 lbf -- for 60 lbf static load. If more than one cable were to bear this load, the tension would decrease dramatically.

- The maximum amount of load transferred from cable tension to coupling support during the one-minute waiting period between measurements was under $200 \mathrm{lbf}$-- just above ten percent of the maximum tension. The load-bearing nature of the couplings adds to EMMA's structural stability.

The maximum pointing uncertainty expected from couplings not sharing stage rotation "perfectly" (i.e. rotations of 35,30 and 25 degrees instead of 30,30 and 30 for a total of 90) is three inches. This means that if one assumes three couplings sharing rotation perfectly, we could predict end-effector position to within three inches after a 90-degree rotation. An example is shown in Figure 2 (all data is given in Appendix B). Such predictions simplify analysis, and suggest that good pointing accuracy can be achieved even through coarse motion commands. 
Figure 2. Example of Stage One Tension and Coupling Effort
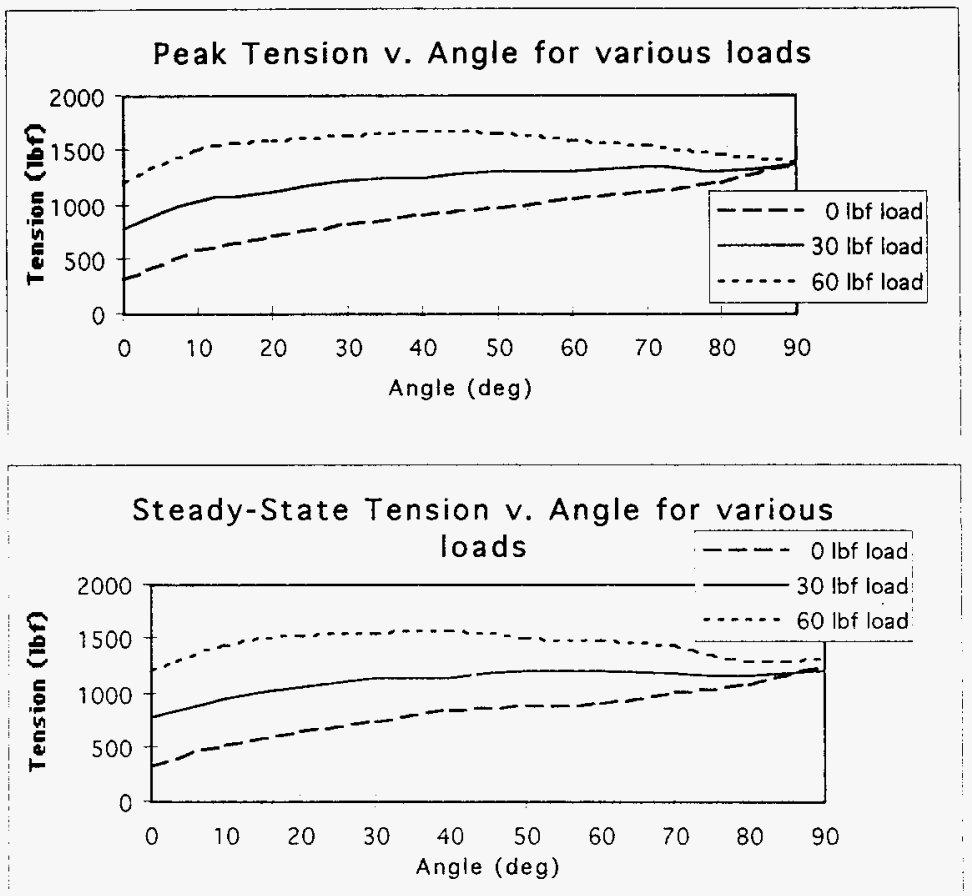
One important point to note is that with a single cable supporting the EMMA and its static load, there was a tendency for the EMMA to twist at large rotations, thus changing the end-effector position. A second cable is sufficient to overcome this twist, which is the prime contributor to the three-inch prediction above, and make the resulting prediction of accuracy much finer.

\section{Stage Two Preparation}

The test was repeated for Case \#1 (for the stage two) -- in this case, stage one was locked by six cables in tension and stage two supported by a single cable, again at $12 \mathrm{o}^{\prime} \mathrm{clock}$. For this test, since the sag in stage one was a function of static load, three sets of targets were drawn on the board, one for each load. Once again, the application of those loads was randomized to remove time-varying effects from the data.

\section{Stage Two Conclusions}

For stage two, the following trends were observed:

- Maximum cable tension was not as strongly a function of static load as of rotation angle. This shows that as rotation angle increases, proportion of load due to resistance of couplings to rotation increases dramatically. The couplings behave as nonlinear clock-springs under preload.

- Repeatability was so good, both for cable tension and rotation of individual couplings, that the test runs were only performed twice for each static load.

- Once again, a coarse approximation of individual coupling rotations -- and thus, a coarse motion command -- can achieve pointing accuracy to within less than three inches.

It's important to recognize that coarse accuracy is achievable using only a single cable to support EMMA and its static load. say to a stage, "rotate 90 degrees at your fastest rate, while bearing your load with one cable instead of all six cables working in concert," and the end-effector happens to get to within three inches of a desired final position. Much finer accuracy may be achieved with very little effort.

In Appendix A are included scaled up maximum cable tension and coupling loads for four larger versions of EMMA: 30 feet in length (with either 0.5 or 1.5 feet radius); and 60 feet in length with 1.5 feet in radius. 


\subsection{Dynamic Cable Tension Requirements and Scale-up}

Preparation

This series of tests will be performed with a small rotating machine (weighing less than about 30 lbf) holding an eccentric load (weighing less than about 1 lbf, and offset from the rotational axis by less than about three inches) attached to the end of the stage two. Exact specs of the rotating machine are still under discussion, and should be resolved in a week.

The rotating machine used was one of the winches intended for demonstration for section 4.0 on EMMA-A. When wired to a VARIAC voltage regulator, this winch was capable of delivering rotational frequencies from 0.1 to $1.0 \mathrm{~Hz}$ with good accuracy and repeatability. Mounted on the winch's shaft was a rotating eccentric weight -- the offset could be varied but was held constant at one foot; the weight was set to five or ten lbf.

Seven dynamic load frequencies to be examined: 0.01 , $0.02,0.05,0.1,0.2,0.5,1 \mathrm{~Hz}$. These frequencies are chosen to be within the capability of whatever rotating machine is used in the tests; and to represent a selection of frequencies expected to be in the neighborhood of EMMA resonance. Higher frequencies will be added if needed.

Unfortunately, frequencies above $1.0 \mathrm{~Hz}$ were beyond the speed capability of this winch; and frequencies below $0.1 \mathrm{~Hz}$ were beyond the winch's resolution. During testing, however, we learned that $1.0 \mathrm{~Hz}$ was sufficiently close to EMMA-B's resonant frequency (found to be in the range of 3.0 to $4.0 \mathrm{~Hz}$ ) that $1.0 \mathrm{~Hz}$ could be used to estimate resonance characteristics without shaking loose the measurement apparatus. We further found that frequencies below $0.1 \mathrm{~Hz}$ did not excite EMMA at all.

We were able to add another form of test to the one originally proposed here, based on the control we had on the winch: by suddenly stopping the winch, we were able to induce a freevibration transient, from which could be deduced the natural frequency and damping ratio of the fundamental mode.

Three position cases will be considered:

- Case \#1: stage one rotated 90 degrees to vertical; stage two in-line

- Case \#2: stage one rotated 90 degrees horizontally; stage two in-line 
- Case \#3: stage one rotated 90 degrees horizontally; stage two rotated 90 degrees in the opposite direction ("s-curve")

These position cases are probably the worst cases that will be faced by a two-stage EMMA.

While these position cases are arguably the worst cases in terms of dynamic response, they were found to be insufficient for completing the test. The reason was that, given the short range of excitation frequencies available from the winch, more data points were needed from other parameters.

Two mountings of dynamic load (both normal to axis of stage two): rotational axis in plane of manipulator and rotational axis normal to manipulator plane. These mountings will ensure end-effector displacement in two directions normal to the stage two axis.

Two mountings did not supply extra parameters for testing, since a rotating eccertric mass already provides excitation in two directions.

Four cable tensions to be tested: $750,1000,1250,1500$ lbf; for a total of sixteen tests.

These cable tensions were immeasurable. While there are now load cells available at NIST for tension feedback, it was impossible to obtain and install them in time to complete the testing. For this reason, it was necessary to set cable tensions in a more subjective way: with the use of a tuning fork to judge their pitch. Since such measurements come with inherent uncertainty, it was necessary to scale back to two types of tension: "high" and "low." Extra test runs were obtained, however, by mixing the tension combination between stage one and stage two (e.g. stage one high/stage two low, etc.). The orientations for two runs under this test are illustrated in Figure 3.

Seven runs per test, sixteen tests is 112 runs total. Each will be carried out over sufficient duration to ensure steady-state oscillation. Each run will be repeated as necessary to ensure repeatability of result.

It was questionable whether 112 runs would tell us significantly more than we could learn in a few -- especially since our measurement apparatus (which was not designed for this application) was by no means certain to complete the test. (The apparatus is shown in Figure 4.) Instead, we opted to envelope the dynamic behavior of the manipulator with a Taguchi-style experiment design. Given a final selection of seven parameters (namely, stage one and stage two cable tension; azimuth and elevation of each stage; and weight of eccentric mass to the winch), we could envelope the dynamic behavior of EMMA-B with eight test runs. To convince ourselves of the validity of those 


\section{WHC-SD-VM-TD-012, Rev 0}

runs, we actually made $11-$ and the combinations of experiment parameters associated with those runs are listed in Appendix $c$.

Conclusions

The results of those 11 runs -- in terms of natural frequency, damping ratio and amplitude of free vibration; and of amplitude of response to winch motion are also given in Appendices $C$ and $D$. The highlights of the results are as follows:

- The natural frequency of vibration for each run was in the 3.0 to $4.0 \mathrm{~Hz}$ range, which indicates at least that the parameters studied here (especially tension) could not be varied to such extremes as to yield significant differences in frequency. It should be noted, however, that the tensions chosen fell within what is expected to be an operating range for an EMMA of this size, and the operating range will be limited by design.

- The damping ratio for free vibration falls within the 10 to 35 percent range for each run, and is most significantly impacted by dynamic load (the larger the offset weight, the more highly damped the mode); and by manipulator position (the tighter the curve, the more highly damped the mode). As we saw in the test under section 2.0, the couplings had greater stiffness when EMMA is fully extended; this result shows the couplings provide more damping when EMMA is contracted into a tight curve.

- The amplitude of free vibration was greatest for a case where stage one was rotated 90 degrees to vertical and stage two kept in-line. For this case, the peak-to-peak amplitude was 5.4 inches. For seven of the 11 runs, the peak-to-peak amplitude did not exceed $11 / 2$ inches.

As for scaling up to a 30-foot version of EMMA, we made the following assumption: that the modal damping ratio is matched. This assumption is likely, given that the static test scale-up matches stiffness -- and that the couplings provide both. For the case which provides the largest vibration amplitude, if EMMA were scaled up to 30 feet and the same excitation provided, the likely result is (in rough terms) a frequency of (still) about $3.0 \mathrm{~Hz}$ and a peak-to-peak amplitude of about two feet at that frequency.

One should keep in mind that it takes a large rotating weight, with a large offset, to cause such vibration. A scenario such as that demonstrated in this test is unlikely to occur in service. The CSEE (for sake of comparison) provides 70 lbf of dynamic load at $100 \mathrm{~Hz}$. This dynamic load is separated from EMMA resonance. EMMA will not break under such loads, and the manipulator can also attenuate vibration if its control system is used to manipulate cable tension (and thus stiffness) in response to unwanted motion. For this reason, EMMA can be designed to be robust. 
Figure 3. Orientations for two Dynamic Test Runs.

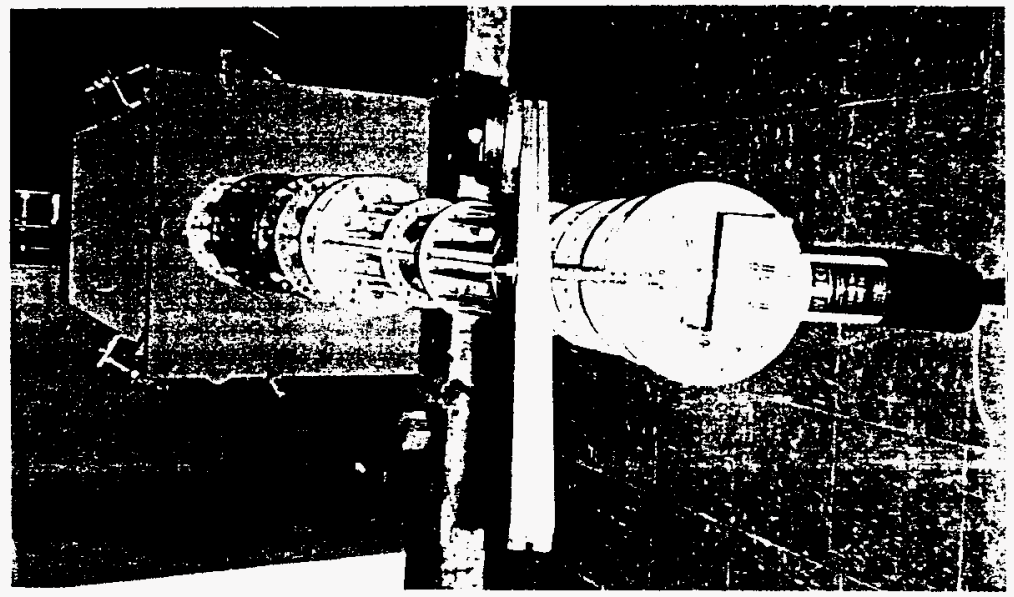

Runs \#1A, 1B and 1C

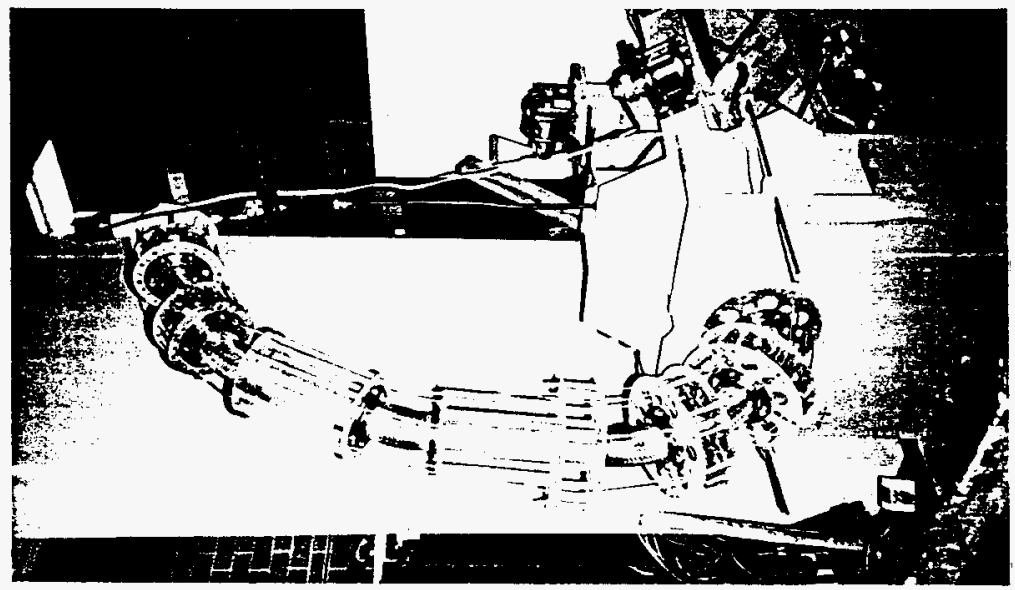

Run \#5 
WHC-SD-WM-TD-012, ReV 0

Figure 4. Dynamic Test Measurement Apparatus.

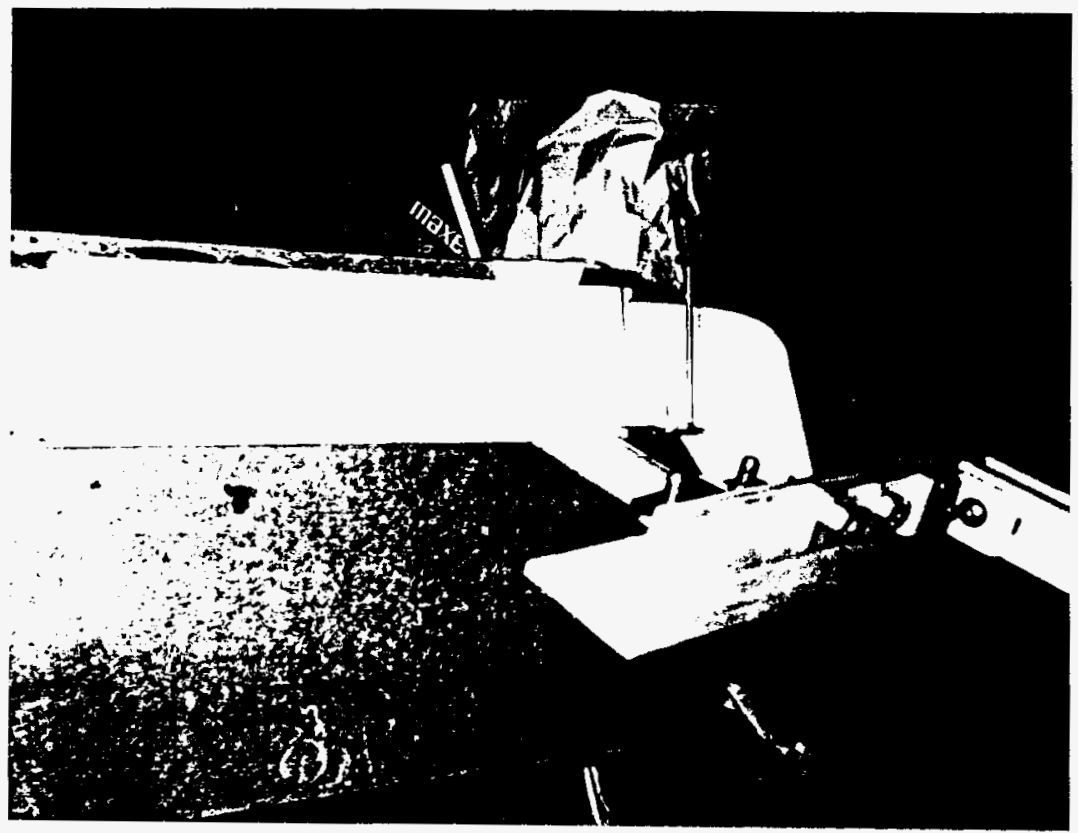

BEST AVAILABLE COPY 


\subsection{Kinematics and Control}

\section{Preparation}

This series of tests will be performed with electric winches engaged to stage one. A preliminary joystick design has been successfully tested with the six.winches on stage one, and now the previous testing will be extended in the following ways:

- The joystick will be calibrated to ensure no winch motion with the joystick at the neutral position.

- The joystick will be used to rotate stage one 90 degrees alternately along two different directions, with cable tension monitored in the shortest cable.

Six more winches. will be added to stage two section, and the joystick operation will be tested on stage two section in the same ways.

The joystick, shown in Figure 5, while working very well in its own right, was poorly matched to the winches mounted on EMMA-A. Those winches do not have appropriate resolution for joystick control. We found we were able to move stage one with the joystick in control, and actually could move at a very small rate (we didn't measure it -- but it would allow for small stand-off accuracy such as the 0.25 inches desired for the CSEE). We learned, however, that because the joystick resolution was so much finer than that of the winches, the winches could only be made to cease motion with the joystick at rest with great difficulty.

\section{Conclusions}

Since the winches mounted on EMMA-A will not prove suitable for final versions of EMMA (either for NIST or WHC), their lack of resolution is not considered a problem. It did, however, teach us how to improve the control system design:

- A dead zone (associated with winch brakes) would ensure that the winches would not turn on unless some minimum motion of the joystick were sensed. (Winches with somewhat finer resolution could still achieve stand-off accuracy.)

- Combined joystick control (for positioning) and load cell feedback with computer control (for tension balancing) would make the next generation of EMMA control robust. Since the initial joystick testing was completed, some load cells were installed and their feedback used to successfully control EMMA in tension. (The updated control system hardware is shown in 
Figure 6.) A likely procedure for the control system would be as follows:

1) EMMA kept nominally under tension control for disturbance rejection.

2) When the joystick is manipulated, continued tension feedback enables the cables to be let out or pulled in by the winches while still being kept close to desired tension.

3) When joystick is released, pure tension control is reinstated.

We intend for future control of EMMA to be governed by a graphical user interface (such as is afforded by LabVIEW) and to in part rely on a kinematics model (such as is afforded by TGRIP) for precise motion determination. Such a system is currently used with the NIST Robocrane.

Figure 5. Prototype of Joystick used for Testing.

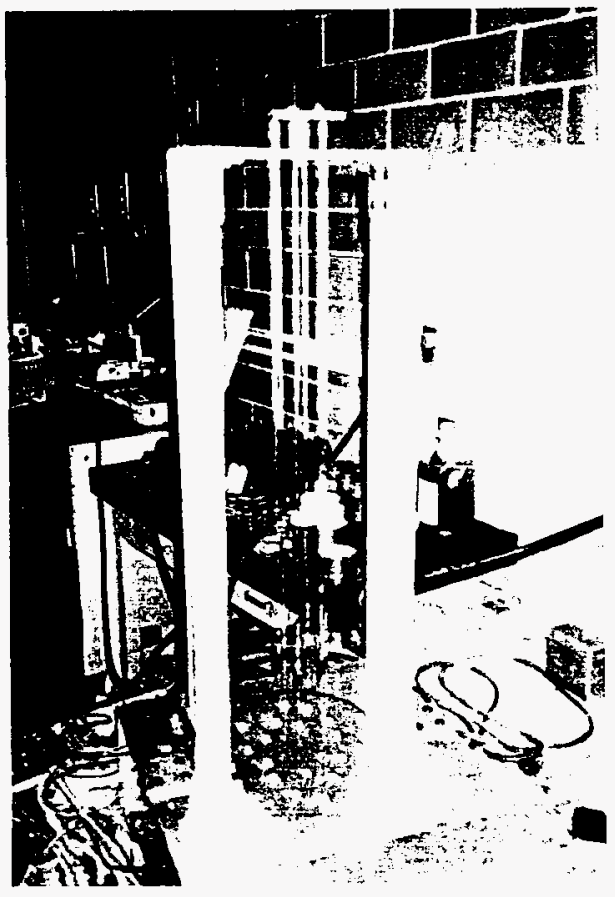


WHC-SD-WM-TD-012, Rev 0

Figure 6. Updated Joystick/Load Cells Control Hardware.

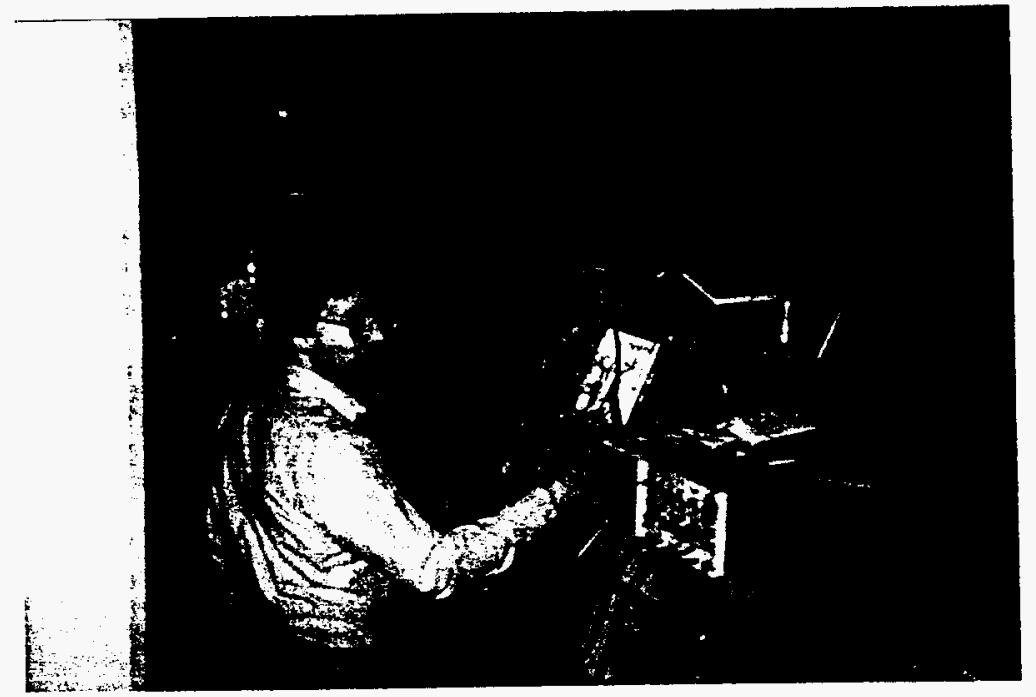




\subsection{Pretension and stability}

Preparation

The primary data necessary for testing here is as follows:

- observations of stage one cable conduit behavior in tests under other sections;

- observations of winch suitability in tests performed in section 4.0 .

A pull cable system, consisting of conduit and cable, as shown in Figure 7, is highly desirable for final versions of EMMA, both for WHC and NIST. Although we have shown that conduit will isolate stage one motion from stage two cables, the conduit and cable we have were not specifically designed for use with one another. In an engineered system, there would be a specification on the amount of tension that can be lost by the cable to the conduit, given the length of conduit and amount of tension.

\section{Conclusions}

We had no such spec during testing, and excessive tension was lost to the conduit we used in these tests. A vendor has since been identified for the pull cable system we need. This system will improve pull cable performance a great deal.

We have observed that such a system, even though it may perform well under curves at its minimum bend radius, also improves in performance when conduit is mounted with smooth, gentle curves. with such mounting, conduit also allows better access to other control components than if the mounting were rigid.

Observations of cable conduit indicate that it is suitable for running stage two cable through stage one and medial stages (and medial through stage one) without stage two cable (or medial) being adversely impacted by stage one motion. 


$$
\text { WHC-SD-WM-TD-012, Rev } 0
$$

Figure 7. Conduit and Winches on EMMA-A.

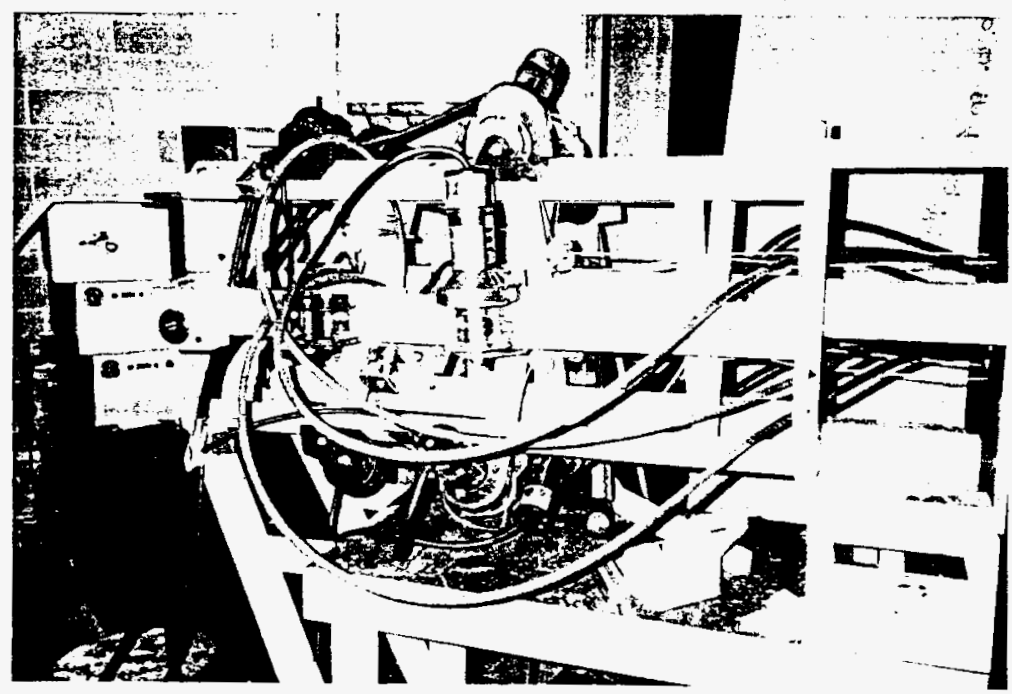




\section{Appendix A. Static Scale-up Results.}

\section{Instructions :}

1) Segment length and weight/unit length, static load and cable tension from test results.

2) Choose desired scale-up characteristics as indicated above.

3 ) We are scaling up from two stages to three. With three stages, the third is outermost.

4) Calculations are based on a 90-degree rotation.

5) Stage three loads can be larger, if larger angles are used.

6) Stage two based on stage one tension obtained from test.

7) Stage two test radius assumed to be average of stages one and three.

\section{Stage one of 30-foot EMMA}

\begin{tabular}{|c|c|c|c|c|c|c|c|c|c|c|c|}
\hline \multicolumn{6}{|c|}{ EMMA characteristics } & \multicolumn{2}{|c|}{ Weight } & \multicolumn{2}{|c|}{ Coupling } & \multicolumn{2}{|l|}{ Cable } \\
\hline \multicolumn{2}{|c|}{$\begin{array}{l}\text { Diameter } \\
\text { (ft) }\end{array}$} & \multicolumn{2}{|c|}{$\begin{array}{l}\text { Wt/length } \\
(1 \mathrm{~b} f / f t)\end{array}$} & \multicolumn{2}{|c|}{$\begin{array}{l}\text { Static Load } \\
\text { (lbf) }\end{array}$} & \multicolumn{2}{|c|}{$\begin{array}{l}\text { Moment } \\
(\text { lbf-ft) }\end{array}$} & \multicolumn{2}{|c|}{$\begin{array}{l}\text { Moment } \\
\text { ( } 8 \text { of total) }\end{array}$} & \multicolumn{2}{|c|}{$\begin{array}{l}\text { Tension } \\
\text { (lbf) }\end{array}$} \\
\hline Test & Scaled & Test & Scaled & Test & Scaled & Test & Scaled & Test & Scaled & Test & Scaled \\
\hline 1 & 1 & 12 & 20 & 30 & 30 & 203 & 2863 & 85 & 60 & 1400 & 8572 \\
\hline 1 & 1 & 12 & 25 & 30 & 30 & 203 & 3541 & 85 & 60 & 1400 & 10603 \\
\hline 1 & 3 & 12 & 20 & 30 & 30 & 203 & 2863 & 85 & 60 & 1400 & 2857 \\
\hline 1 & 3 & 12 & 25 & 30 & 30 & 203 & 3541 & 85 & 60 & 1400 & 3534 \\
\hline 1 & 1 & 12 & 20 & 60 & 60 & 258 & 3013 & 82 & 60 & 1400 & 7405 \\
\hline 1 & 1 & 12 & $25^{\circ}$ & 60 & 60 & 258 & 3691 & 82 & 60 & 1400 & 9072 \\
\hline 1 & 3 & 12 & 20 & 60 & 60 & 258 & 3013 & 82 & 60 & 1400 & 2468 \\
\hline 1 & 3 & 12 & 25 & 60 & 60 & 258 & 3691 & 82 & 60 & 1400 & 3024 \\
\hline 1 & 1 & 12 & 20 & 60 & 100 & 258 & 3213 & 82 & 60 & 1400 & 7896 \\
\hline 1 & 1 & 12 & 25 & 60 & 100 & 258 & 3891 & 82 & 60 & 1400 & 9563 \\
\hline 1 & 3 & 12 & 20 & 60 & 100 & 258 & 3213 & 82 & 60 & 1400 & 2632 \\
\hline 1 & 3 & 12 & 25 & 60 & 100 & 258 & 3891 & 82 & 60 & 1400 & 3188 \\
\hline
\end{tabular}




\section{Static scale-up Results (continued)}

Instructions :

1) Segment length and weight/unit length, static load and cable tension from test results.

2) Choose desired scale-up characteristics as indicated above.

3) We are scaling up from two stages to three. With three stages, the third is outermost.

4) Calculations are based on a 90-degree rotation.

5) Stage three loads can be larger, if larger angles are used.

6) Stage two based on stage one tension obtained from test.

7) Stage two test radius assumed to be average of stages one and three.

\section{Stage Two of 30-foot EMMA}

\begin{tabular}{|c|c|c|c|c|c|c|c|c|c|c|c|}
\hline \multicolumn{6}{|c|}{ EMMA characteristics } & \multicolumn{2}{|c|}{ Weight } & \multirow{2}{*}{\multicolumn{2}{|c|}{$\begin{array}{l}\text { Coupling } \\
\text { Moment }\end{array}$}} & \multicolumn{2}{|c|}{ Cable } \\
\hline \multicolumn{2}{|c|}{$\begin{array}{l}\text { Diameter } \\
(\mathrm{ft})\end{array}$} & \multicolumn{2}{|c|}{$\begin{array}{l}\text { Wt/length } \\
(1 \mathrm{~b} f / \mathrm{ft})\end{array}$} & \multicolumn{2}{|c|}{$\begin{array}{l}\text { Static Load } \\
\text { (lbf) }\end{array}$} & \multicolumn{2}{|c|}{$\begin{array}{l}\text { Moment } \\
\text { (lbf-ft) }\end{array}$} & & & \multicolumn{2}{|c|}{$\begin{array}{l}\text { Tension } \\
\text { (lbf) }\end{array}$} \\
\hline Test & Scaled & Test & Scaled & Test & Scaled & Test & Scaled & Test & Scaled & Test & Scaled \\
\hline 1 & 1 & 12 & 20 & 30 & 30 & 111 & 1850 & 92 & 60 & 1400 & 8098 \\
\hline 1 & 1 & 12 & 25 & 30 & 30 & 111 & 2275 & 92 & 60 & 1400 & 9958 \\
\hline 1 & 3 & 12 & 20 & 30 & 30 & 111 & 1850 & 92 & 60 & 1400 & 2699 \\
\hline 1 & 3 & 12 & 25 & 30 & 30 & 111 & 2275 & 92 & 60 & 1400 & 3319 \\
\hline 1 & 1 & 12 & 20 & 60 & 60 & 166 & 2000 & 88 & 60 & 1400 & 6173 \\
\hline 1 & 1 & 12 & 25 & 60 & 60 & 166 & 2425 & 88 & 60 & 1400 & 7485 \\
\hline 1 & 3 . & 12 & 20 & 60 & 60 & 166 & 2000 & 88 & 60 & 1400 & 2058 \\
\hline 1 & 3 & 12 & 25 & 60 & 60 & 166 & 2425 & 88 & 60 & 1400 & 2495 \\
\hline 1 & 1 & 12 & 20 & 60 & 100 & 166 & 2200 & 88 & 60 & 1400 & 6790 \\
\hline 1 & 1 & 12 & 25 & 60 & 100 & 166 & 2625 & 88 & 60 & 1400 & 8102 \\
\hline 1 & 3 & 12 & 20 & 60 & 100 & 166 & 2200 & 88 & 60 & 1400 & 2263 \\
\hline 1 & 3 & 12 & 25 & 60 & 100 & 166 & 2625 & 88 & 60 & 1400 & 2701 \\
\hline
\end{tabular}




\section{Static Scale-up Results (continued)}

Instructions :

1) Segment length and weight/unit length, static load and cable tension from test results.

2) Choose desired scale-up characteristics as indicated above.

3) We are scaling up from two stages to three. With three stages, the third is outermost.

4) Calculations are based on a 90-degree rotation.

5) Stage three loads can be larger, if larger angles are used.

6) Stage two based on stage one tension obtained from test.

7) Stage two test radius assumed to be average of stages one and three.

\section{Stage Three of 30-foot EMMA}

\begin{tabular}{|c|c|c|c|c|c|c|c|c|c|c|c|}
\hline \multicolumn{6}{|c|}{ EMMA characteristics } & & \multicolumn{2}{|c|}{ Coupling } & \multicolumn{2}{|c|}{ Cable } \\
\hline \multicolumn{2}{|c|}{$\begin{array}{l}\text { Diameter } \\
\text { (ft) }\end{array}$} & \multicolumn{2}{|c|}{$\begin{array}{l}\text { Wt/length } \\
\text { (lbf/ft) }\end{array}$} & \multicolumn{2}{|c|}{$\begin{array}{l}\text { Static Load } \\
\text { (lbf) }\end{array}$} & \multicolumn{2}{|c|}{$\begin{array}{l}\text { Moment } \\
\text { (lbf-ft) }\end{array}$} & \multicolumn{2}{|c|}{$\begin{array}{l}\text { Moment } \\
\text { ( } 8 \text { of total) }\end{array}$} & \multicolumn{2}{|c|}{$\begin{array}{l}\text { Tension } \\
\text { (lbf) }\end{array}$} \\
\hline Test & Scaled & Test & Scaled & Test & Scaled & Test & Scaled & Test & Scaled & Test & Scaled \\
\hline 1 & 1 & 12 & 20 & 30 & 30 & 116 & 1550 & 93 & 60 & 1700 & 6446 \\
\hline 1 & 1 & 12 & 25 & 30 & 30 & 116 & 1900 & 93 & 60 & 1700 & 7902 \\
\hline 1 & 3 & 12 & 20 & 30 & 30 & 116 & 1550 & 93 & 60 & 1700 & 2149 \\
\hline 1 & 3 & 12 & 25 & 30 & 30 & 116 & 1900 & 93 & 60 & 1700 & 2634 \\
\hline 1 & 1 & 12 & 20 & 60 & 60 & 171 & 1700 & 90 & 60 & 1700 & 5063 \\
\hline 1 & 1 & 12 & 25 & 60 & 60 & 171 & 2050 & 90 & 60 & 1700 & 6105 \\
\hline 1 & 3 & 12 & 20 & 60 & 60 & 171 & 1700 & 90 & 60 & 1700 & 1688 \\
\hline 1 & 3 & 12 & 25 & 60 & 60 & 171 & 2050 & 90 & 60 & 1700 & 2035 \\
\hline 1 & 1 & 12 & 20 & 60 & 100 & 171 & 1900 & 90 & 60 & 1700 & 5658 \\
\hline 1 & 1 & 12 & 25 & 60 & 100 & 171 & 2250 & 90 & 60 & 1700 & 6701 \\
\hline 1 & 3 & 12 & 20 & 60 & 100 & 171 & 1900 & 90 & 60 & 1700 & 1886 \\
\hline 1 & 3 & 12 & 25 & 60 & 100 & 171 & 2250 & 90 & 60 & 1700 & 2234 \\
\hline
\end{tabular}




\section{Appendix B. Static Test Results.}

\begin{tabular}{|c|c|c|c|c|c|c|c|c|c|}
\hline Stage & & & 0 & $\mathrm{bbf} L$ & ad & & & & \\
\hline $\begin{array}{l}\text { Angle } \\
\text { (deg) }\end{array}$ & $\begin{array}{l}\text { Initial } \\
\text { Tension } \\
\end{array}$ & $\begin{array}{l}\text { Steady } \\
\text { Tension }\end{array}$ & $\mathrm{Cl}$ & (deg) & $\mathrm{C} 2$ & (deg) & C3 & (deg) & $\begin{array}{l}\text { "Perfect" } \\
\text { (deg) }\end{array}$ \\
\hline 0 & 320 & 320 & & -6 & & 2 & & 5 & 0 \\
\hline 10 & 570 & 525 & & -3 & & 5 & & 8 & 3 \\
\hline 20 & 700 & 640 & & 2 & & 8 & & 11 & 7 \\
\hline 30 & 820 & 740 & & 7 & & 12 & & 12 & 10 \\
\hline 40 & 900 & 830 & & 11 & & 15 & & 14 & 13 \\
\hline 50 & 970 & 875 & & 16 & & 18 & & 16 & 17 \\
\hline 60 & 1045 & 910 & & 21 & & 21 & & 18 & 20 \\
\hline 70 & 1120 & 1020 & & 26 & & 24 & & 20 & 23 \\
\hline 80 & 1210 & 1075 & & 31 & & 27 & & 22 & 27 \\
\hline 90 & 1380 & 1250 & & 36 & & 29 & & 25 & 30 \\
\hline
\end{tabular}

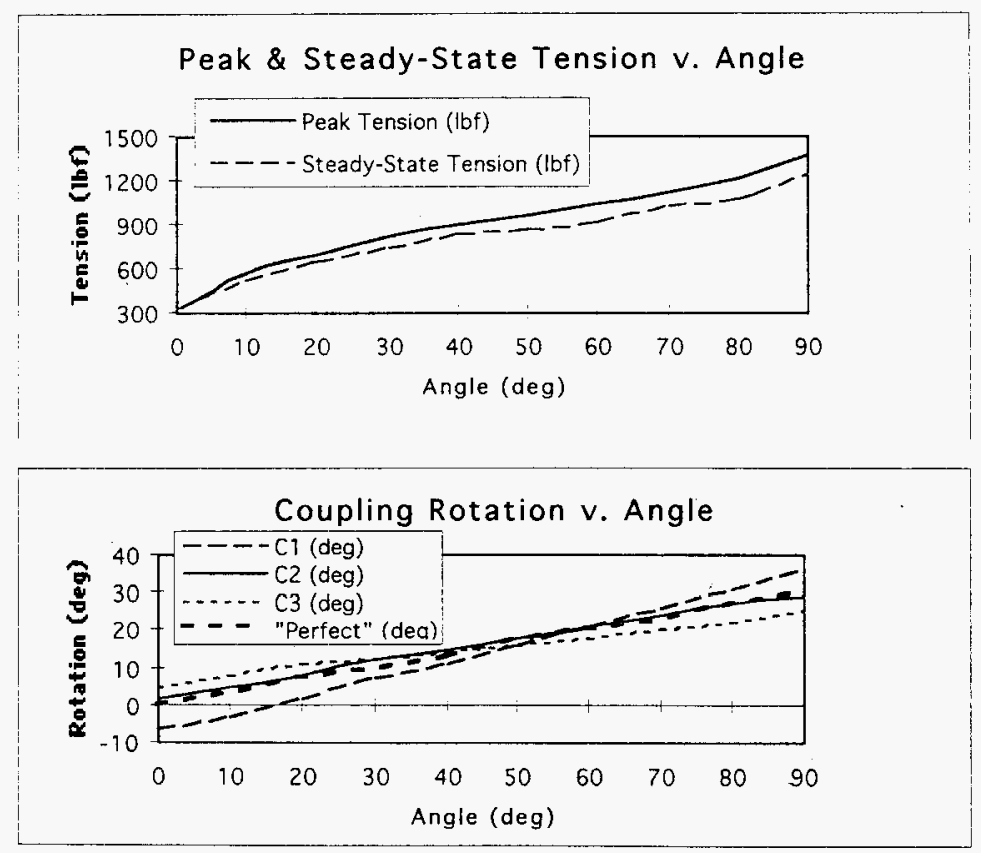


WHC-SD-WM-TD-012, Rev 0

\begin{tabular}{|c|c|c|c|c|c|c|c|c|c|}
\hline \multicolumn{10}{|c|}{ Static Test Results (continued) } \\
\hline \multicolumn{10}{|c|}{ stage one } \\
\hline $\begin{array}{l}\text { Angle } \\
\text { (deg) }\end{array}$ & $\begin{array}{l}\text { Initial } \\
\text { Tension }\end{array}$ & $\begin{array}{l}\text { Steady } \\
\text { Tension }\end{array}$ & $\mathrm{Cl}$ & (deg) & $\mathrm{C} 2$ & (deg) & C3 & (deg) & $\begin{array}{l}\text { "Perfect" } \\
\text { (deg) }\end{array}$ \\
\hline 0 & 770 & 770 & & -7 & & 3 & & 5 & 0 \\
\hline 10 & 1030 & 950 & & -3 & & 6 & & 8 & 3 \\
\hline 20 & 1120 & 1050 & & 0 & & 10 & & 11 & 7 \\
\hline 30 & 1220 & 1140 & & 4 & & 13 & & 15 & 10 \\
\hline 40 & 1250 & 1150 & & 10 & & 14 & & 17 & 13 \\
\hline 50 & 1320 & 1210 & & 15 & & 19 & & 17 & 17 \\
\hline 60 & 1320 & 1210 & & 20 & & 21 & & 20 & 20 \\
\hline 70 & 1360 & 1180 & & 25 & & 24 & & 21 & 23 \\
\hline 80 & 1310 & 1170 & & 31 & & 26 & & 23 & 27 \\
\hline 90 & 1380 & 1200 & & 35 & & 29 & & 26 & 30 \\
\hline
\end{tabular}

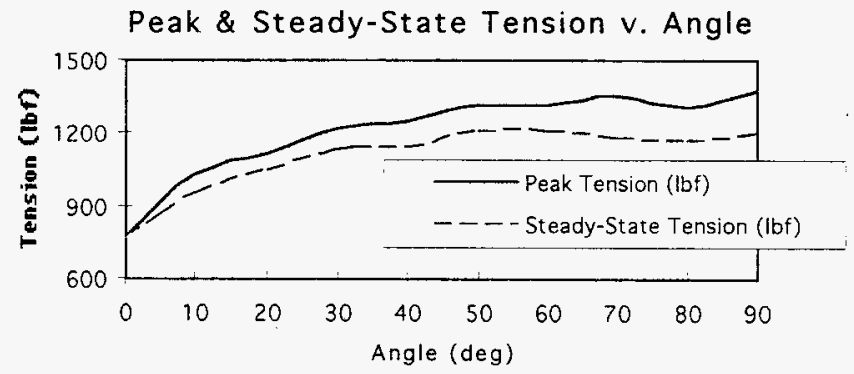

Coupling Rotation v. Angle

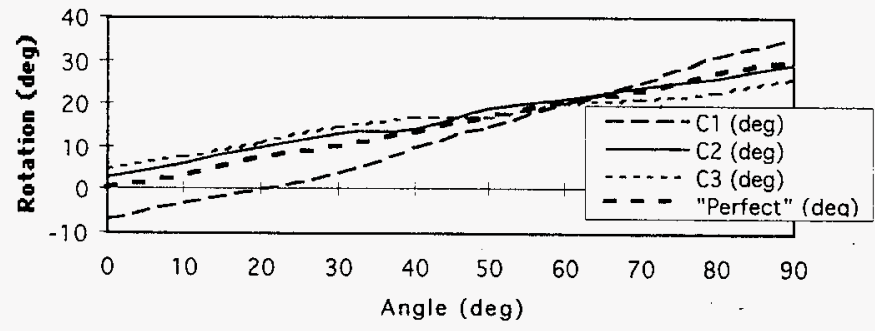


WHC-SD-WM-TD-012, Rev 0

\begin{tabular}{|c|c|c|c|c|c|c|c|c|c|}
\hline \multicolumn{10}{|c|}{ Static Test Results (continued) } \\
\hline $\begin{array}{l}\text { Angle } \\
\text { (deg) }\end{array}$ & $\begin{array}{l}\text { Initial } \\
\text { Tension }\end{array}$ & $\begin{array}{l}\text { Steady } \\
\text { Tension }\end{array}$ & $\mathrm{Cl}$ & (deg) & C2 & (deg) & $\mathrm{C} 3$ & (deg) & $\begin{array}{l}\text { "Perfect" } \\
\text { (deg) }\end{array}$ \\
\hline 0 & 1200 & 1200 & & -9 & & 4 & & 8 & 0 \\
\hline 10 & 1500 & 1440 & & -6 & & 8 & & 10 & 3 \\
\hline 20 & 1590 & 1520 & & 0 & & 11 & & 13 & 7 \\
\hline 30 & 1640 & 1540 & & 4 & & 14 & & 16 & 10 \\
\hline 40 & 1670 & 1570 & & 8 & & 17 & & 18 & 13 \\
\hline 50 & 1650 & 1500 & & 15 & & 18 & & 20 & 17 \\
\hline 60 & 1600 & 1490 & & 19 & & 23 & & 21 & 20 \\
\hline 70 & 1550 & 1450 & & 25 & & 23 & & 24 & 23 \\
\hline 80 & 1470 & 1300 & & 30 & & 26 & & 24 & 27 \\
\hline 90 & 1400 & 1320 & & 35 & & 29 & & 26 & 30 \\
\hline
\end{tabular}
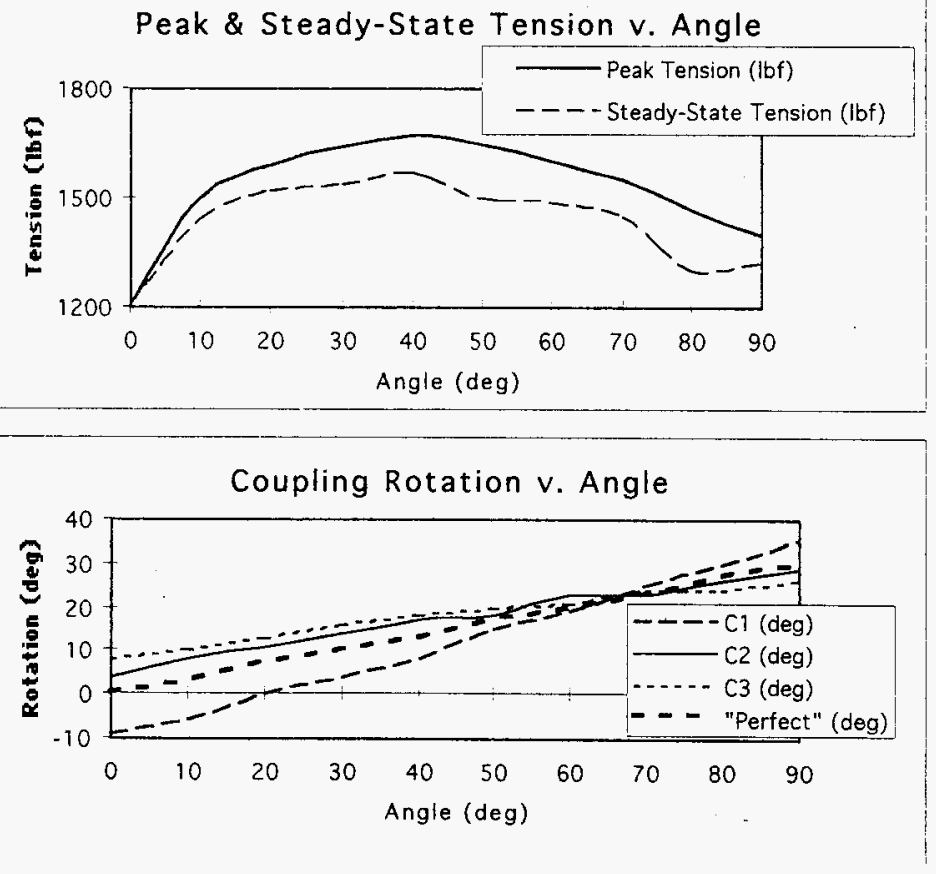
WHC-SD-WM-TD-012, ReV 0

static Test Results (continued)

stage one
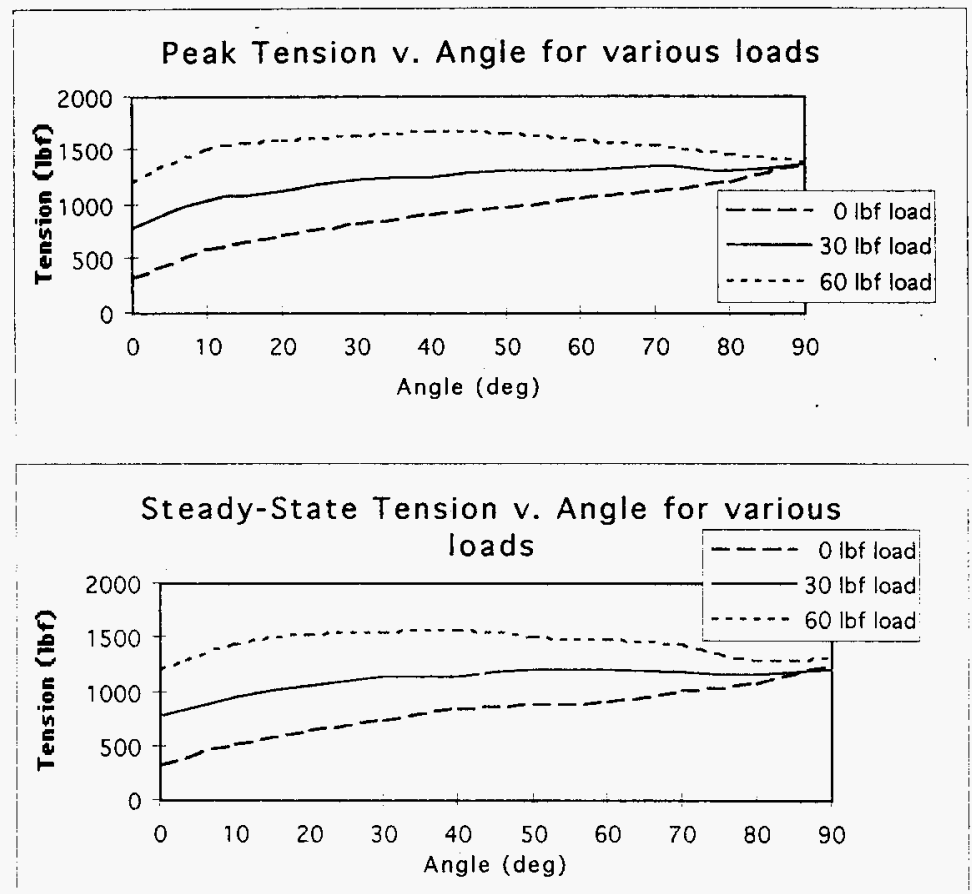
WHC-SD-WM-TD-012, Rev 0

\begin{tabular}{|c|c|c|c|c|c|c|c|c|c|}
\hline \multicolumn{10}{|c|}{ static Test Results (continued) } \\
\hline $\begin{array}{l}\text { Angle } \\
\text { (deg) }\end{array}$ & $\begin{array}{l}\text { Initial } \\
\text { Tension }\end{array}$ & $\begin{array}{l}\text { Steady } \\
\text { Tension }\end{array}$ & $\mathrm{Cl}$ & (deg) & $C 2$ & (deg) & $\mathrm{C} 3$ & (deg) & $\begin{array}{l}\text { "Perfect" } \\
\text { (deg) }\end{array}$ \\
\hline 0 & 0 & 0 & & 0 & & 0 & & 0 & 0 \\
\hline 10 & 65 & 50 & & -1 & & 5 & & 6 & 3 \\
\hline 20 & 250 & 100 & & 1 & & 9 & & 10 & 7 \\
\hline 30 & 350 & 425 & & 4 & & 13 & & 13 & 10 \\
\hline 40 & 475 & 525 & & 7 & & 17 & & 16 & 13 \\
\hline 50 & 590 & 625 & & 10 & & 21 & & 19 & 17 \\
\hline 60 & 690 & 700 & & 14 & & 24 & & 22 & 20 \\
\hline 70 & 815 & 850 & & 18 & & 28 & & 24 & 23 \\
\hline 80 & 940 & 965 & & 22 & & 31 & & 27 & 27 \\
\hline 90 & 1075 & 1100 & & 27 & & 34 & & 29 & 30 \\
\hline 100 & 1240 & 1250 & & 33 & & 36 & & 31 & 33 \\
\hline 110 & 1465 & 1375 & & 40 & & 38 & & 32 & 37 \\
\hline 120 & 1725 & 1650 & & 45 & & 40 & & 35 & 40 \\
\hline
\end{tabular}
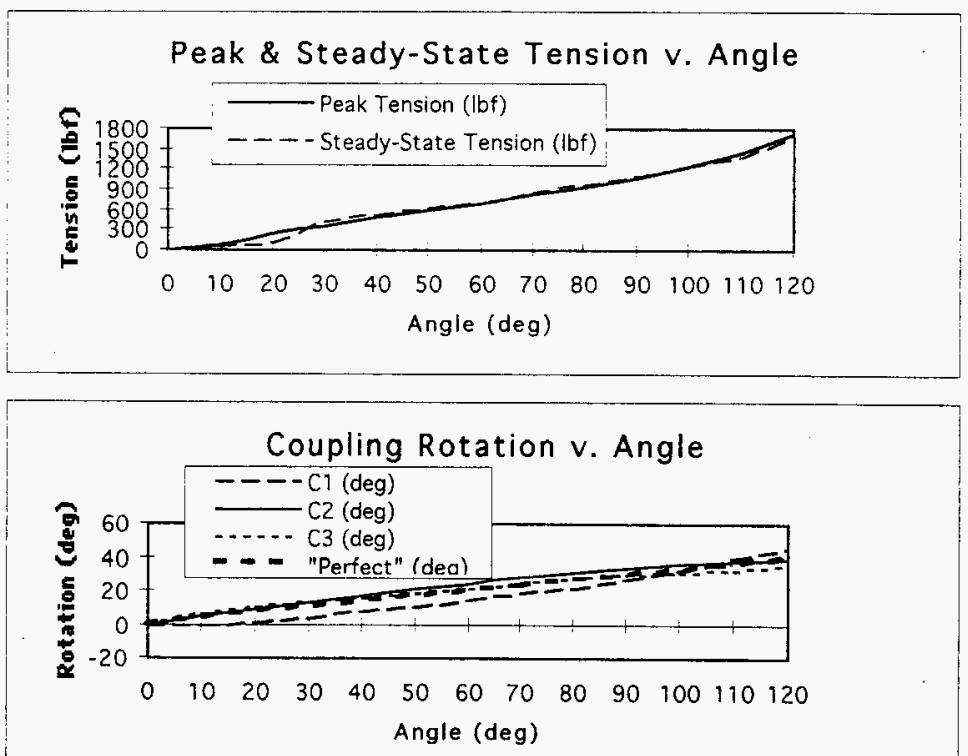
WHC-SD-WM-TD-012, Rev 0

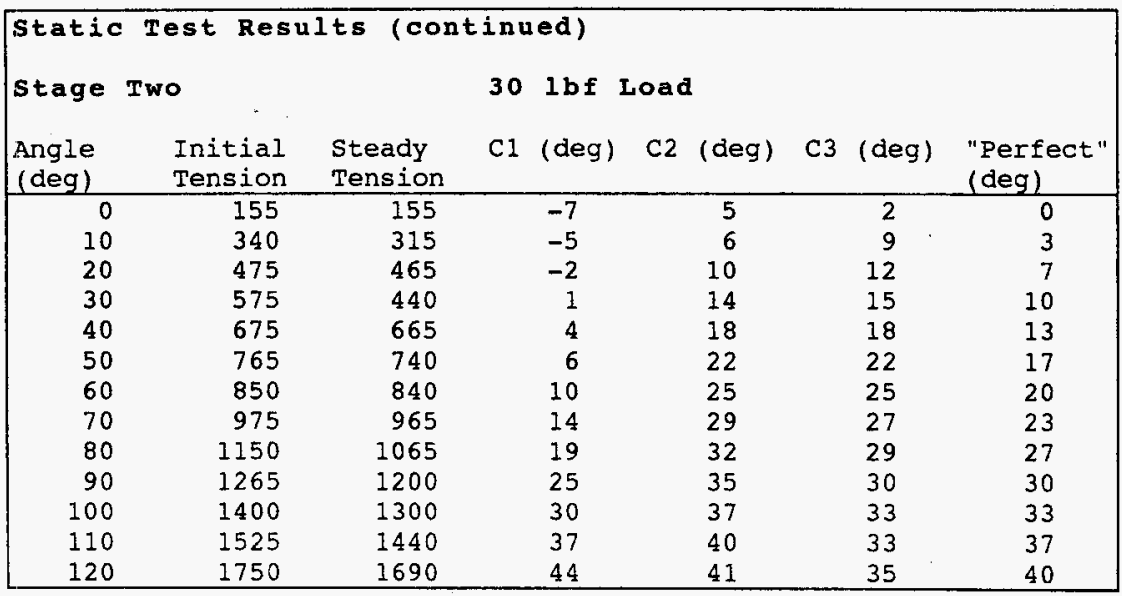
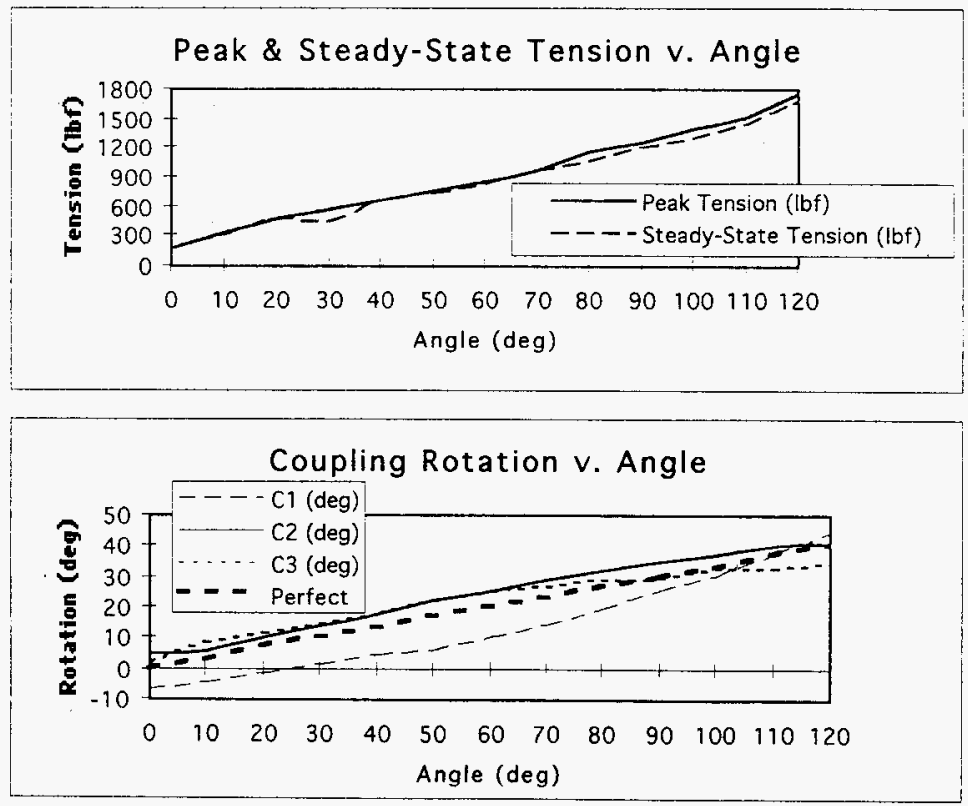
WHC-SD-WM-TD-012, Rev 0

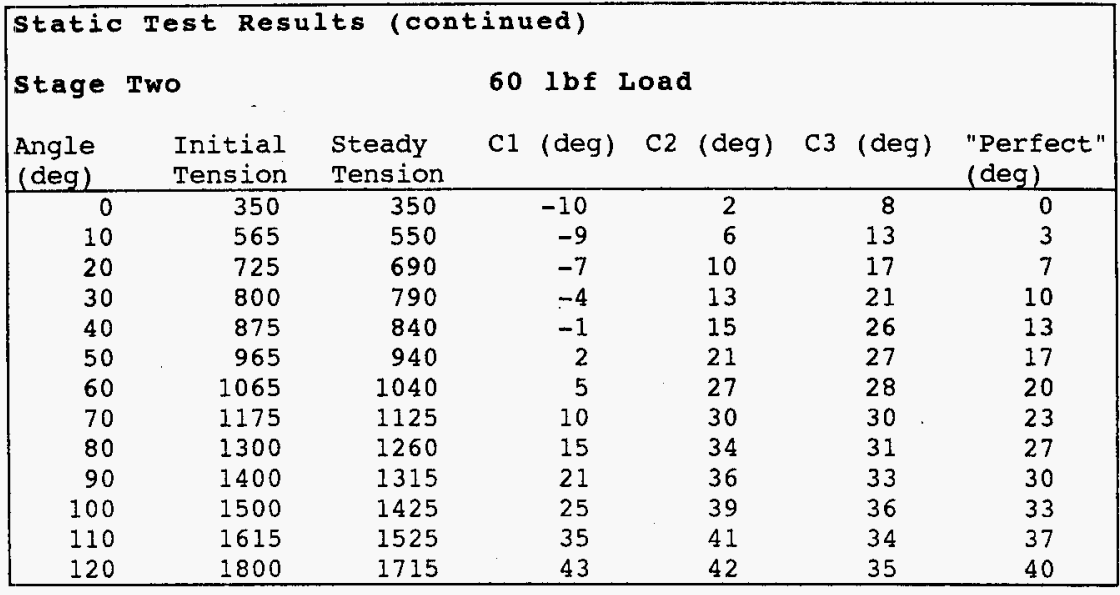

Peak \& Steady-State Tension $v$. Angle

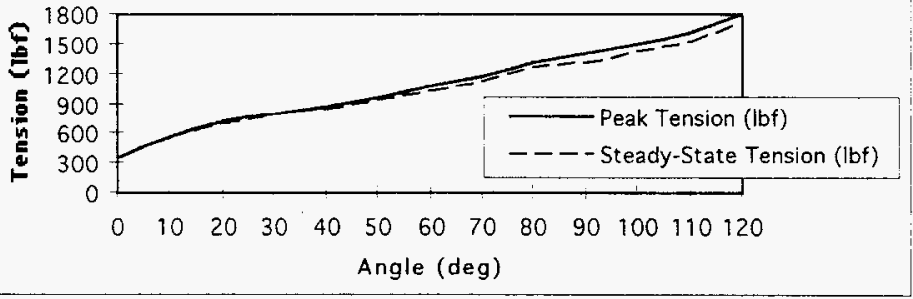

\section{Coupling Rotation v. Angle}

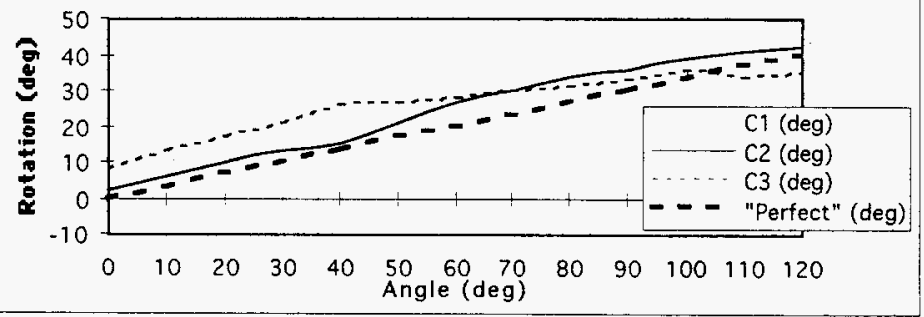


WHC-SD-WM-TD-012, Rev 0

Static Test Results (continued)

Stage Two

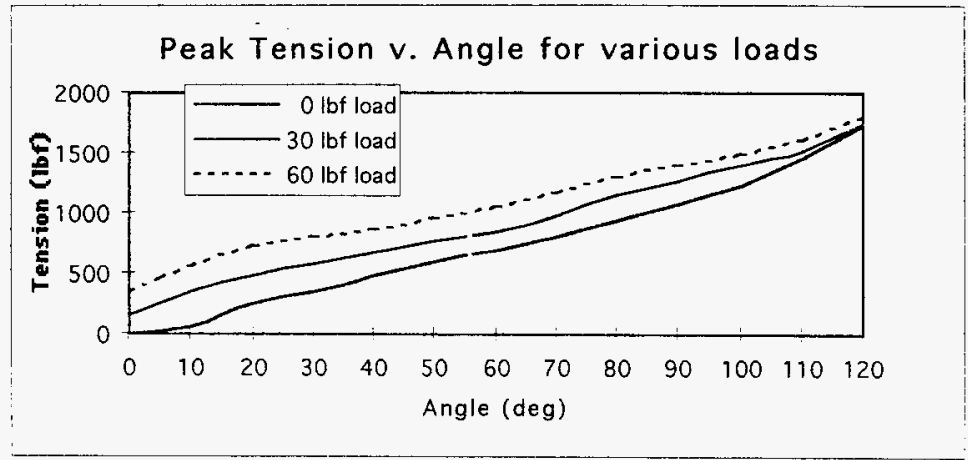

Steady-State Tension v. Angle for various loads

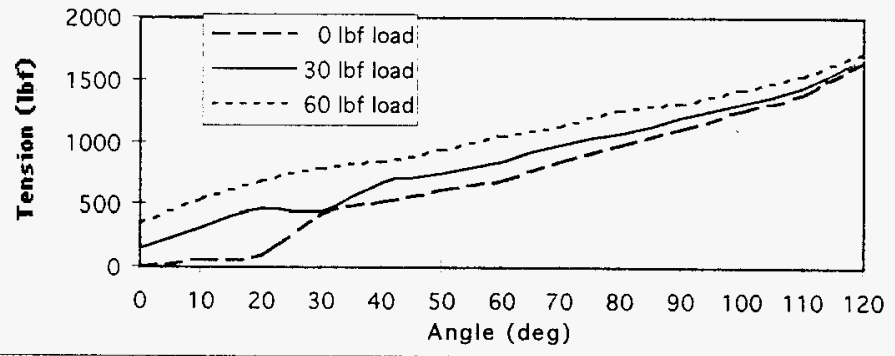




\section{Appendix C. Dynamic Test Results}

\begin{tabular}{|c|c|c|c|c|c|c|c|c|c|}
\hline \multicolumn{10}{|c|}{ Summary of Runs Performed } \\
\hline \multirow[t]{2}{*}{ Run \# } & \multirow[t]{2}{*}{ Load } & \multirow{2}{*}{$\begin{array}{l}\text { Stage } \\
\mathrm{T}\end{array}$} & \multirow{2}{*}{$\begin{array}{c}\text { One } \\
\mathrm{A}\end{array}$} & \multirow{2}{*}{$\underset{\text { E }}{\text { variables }}$} & \multirow{2}{*}{$\begin{array}{l}\text { Stage } \\
\mathrm{T}\end{array}$} & \multirow{2}{*}{$\begin{array}{c}\text { Two } \\
\text { A }\end{array}$} & \multirow{2}{*}{$\begin{array}{c}\text { variables } \\
\text { E }\end{array}$} & \multicolumn{2}{|c|}{ vibration } \\
\hline & & & & & & & & $F$ & D \\
\hline $1 \mathrm{~A}$ & 5 & Low & 0 & 0 & Low & 0 & 0 & 3.5 & 0.11 \\
\hline $1 B$ & 5 & High & 0 & 0 & High & 0 & 0 & 3.8 & 0.17 \\
\hline $1 \mathrm{C}$ & 10 & High & 0 & 0 & High & 0 & 0 & 3.5 & 0.17 \\
\hline 2 & 5 & Low & 45 & 45 & $\mathrm{High}$ & 0 & 90 & 3.0 & 0.24 \\
\hline 3 & 5 & High & 0 & 0 & High & 45 & 45 & 3.4 & 0.10 \\
\hline 4 & 5 & High & 45 & 45 & Low & 90 & 0 & 3.6 & 0.22 \\
\hline 5 & 10 & Low & 0 & 90 & Low & 45 & 45 & 3.2 & 0.32 \\
\hline 6 & 10 & Low & 90 & 0 & High & 90 & 0 & 3.9 & 0.16 \\
\hline 7 & 10 & $\mathrm{Hiqh}$ & 0 & 90 & High & 0 & 0 & 3.2 & 0.32 \\
\hline 8 & 10 & High & 90 & 0 & Low & 0 & 90 & 3.4 & 0.33 \\
\hline 9 & 10 & High & 90 & 90 & High & 90 & 90 & 3.1 & 0.24 \\
\hline
\end{tabular}

Legend:

$\mathrm{T}=$ cable tension, based on subjective measure

$A=$ azimuth, deg

$\mathrm{E}=$ elevation, deg

$\mathrm{F}=$ frequency of free vibration, $\mathrm{Hz}$

$\mathrm{D}=$ damping ratio of free vibration, unitless 


\section{Dynamic Test Results (continued)}

\section{Forced Vibration:}

Measurements taken while rotating mass is in motion

Free vibration:

Measurements taken after rotating mass has stopped

\begin{tabular}{|c|c|c|c|c|c|c|c|c|}
\hline & \multicolumn{8}{|c|}{ Maximum Amplitude (in, peak-to-peak) } \\
\hline & \multicolumn{4}{|c|}{ Forced vibration } & \multicolumn{4}{|c|}{ Free vibration } \\
\hline & \multicolumn{4}{|c|}{ Excitation Erequency $(\mathrm{Hz})$} & \multicolumn{4}{|c|}{ Excitation Frequency $(\mathrm{Hz})$} \\
\hline Run \# & 0.10 & 0.20 & 0.50 & 1.00 & 0.10 & 0.20 & 0.50 & 1.00 \\
\hline $1 \mathrm{~A}$ & 0.22 & 0.38 & 0.48 & 0.58 & 0.05 & 0.15 & 0.22 & 0.58 \\
\hline $1 \mathrm{~B}$ & 0.10 & 0.19 & 0.19 & 0.54 & 0.05 & 0.14 & 0.24 & 0.39 \\
\hline $1 \mathrm{C}$ & 0.17 & 0.34 & 0.49 & 0.79 & 0.05 & 0.14 & 0.24 & 0.79 \\
\hline 2 & 0.05 & 0.25 & 0.43 & 0.51 & 0.14 & 0.18 & 0.33 & 0.51 \\
\hline 3 & 0.05 & 0.26 & 0.55 & 0.90 & 0.19 & 0.19 & 0.28 & 0.60 \\
\hline 4 & 0.05 & 0.05 & 0.19 & 0.21 & 0.11 & 0.17 & 0.19 & 0.21 \\
\hline 5 & 0.05 & 0.35 & 0.62 & 1.60 & 0.05 & 0.18 & 0.28 & 1.60 \\
\hline 6 & 0.05 & 0.25 & 0.45 & 0.70 & 0.05 & 0.05 & 0.15 & 0.30 \\
\hline 7 & 0.23 & 0.63 & 0.86 & 4.10 & 0.23 & 0.29 & 0.86 & 4.10 \\
\hline 8 & 0.32 & 0.60 & 0.76 & 2.75 & 0.32 & 0.34 & 0.62 & 2.75 \\
\hline 9 & 0.19 & 0.64 & 1.16 & 2.00 & 0.05 & 0.11 & 0.30 & 1.50 \\
\hline
\end{tabular}

Notes: Measurements of "0.05" should actually be interpreted as "too small to be seen by the unaided eye" Free Vibration maximum amplitude does not exceed Forced Vibration maximum amplitude 


\section{Dynamic Test Results (continued)}

Notes: We faired curves through the Forced Vibration amplitudes to predict amplitude at $3.5 \mathrm{~Hz}$ excitation frequency. Then we assumed vibration amplitude to scale up linearly. This is a table of Forced Vibration peak-to-peak amplitude, in inches, for two sizes of EMMA and for each set of run conditions.

\begin{tabular}{|llr|}
\hline Run \# & $8 \mathrm{ft}$ & $30 \mathrm{ft}$ \\
\hline $1 \mathrm{~A}$ & 0.78 & 2.93 \\
$1 \mathrm{~B}$ & 0.98 & 3.68 \\
$1 \mathrm{C}$ & 1.32 & 4.95 \\
2 & 0.70 & 2.63 \\
3 & 1.45 & 5.44 \\
4 & 0.30 & 1.13 \\
5 & 2.10 & 7.88 \\
6 & 1.25 & 4.69 \\
7 & 5.40 & 20.25 \\
8 & 3.25 & 12.19 \\
9 & 2.50 & 9.38 \\
\hline
\end{tabular}


Strip charts from Run \#1A

Note: Strip charts are labeled A, B, C and D (e.g. 1AA, 1AB, 1AC, $1 A D)$ to represent an excitation frequency of $0.1,0.2,0.5$ and 1.0 $\mathrm{Hz}$, respectively.

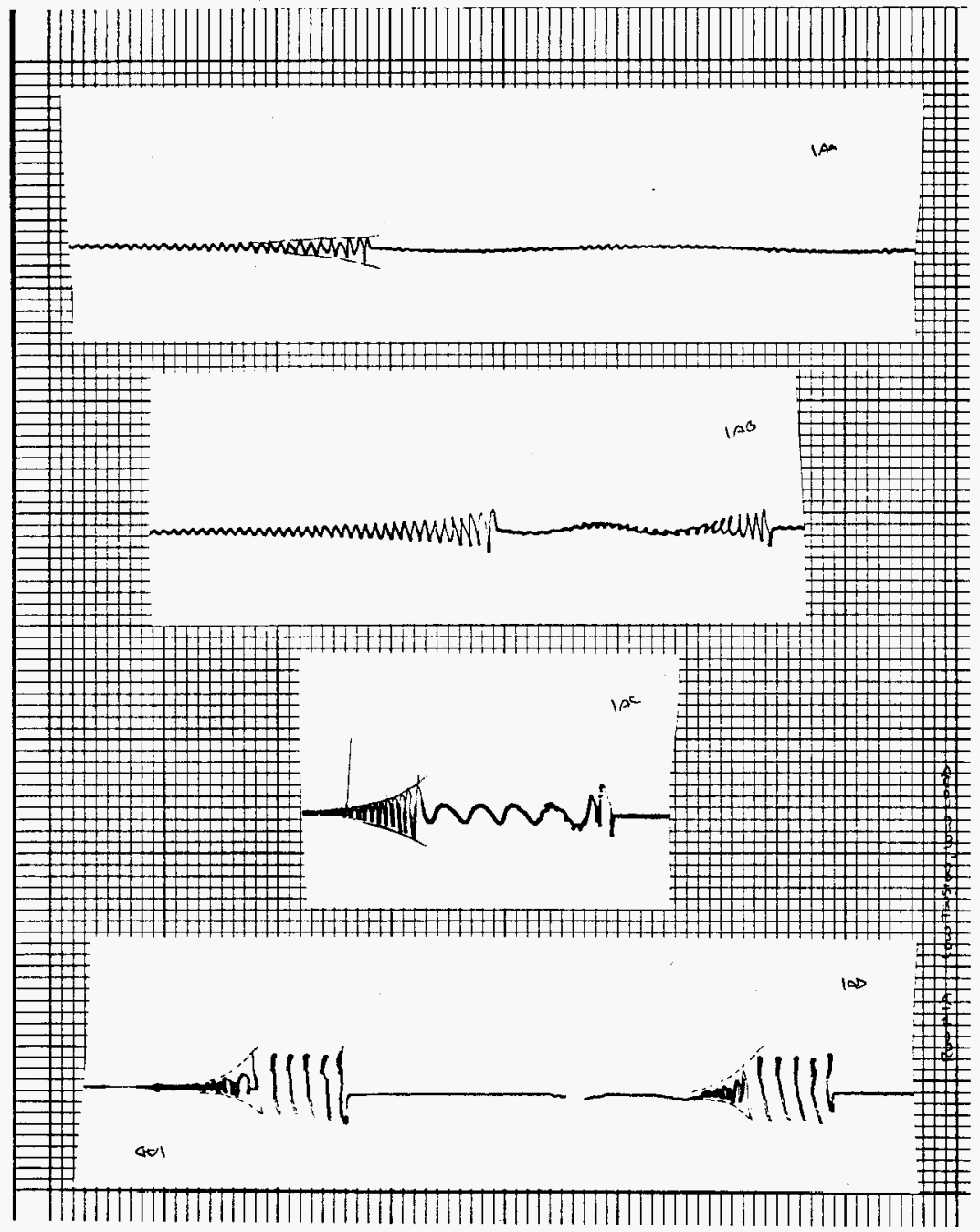


WHC-SD-WM-TD-012, Rev 0

strip charts from Run \#1B

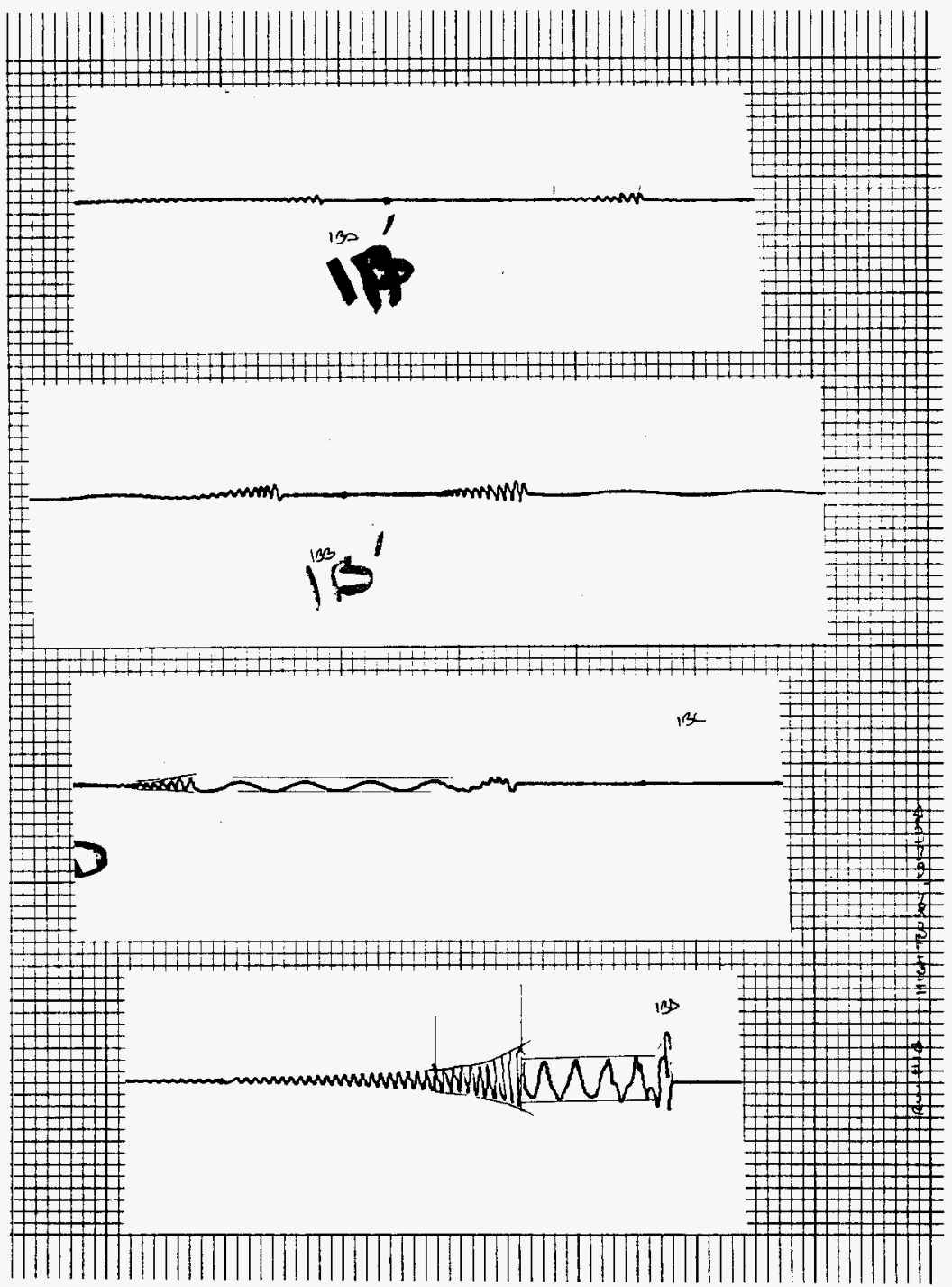


WHC-SD-WM-TD-012, Rev 0

strip charts from Run \#1C

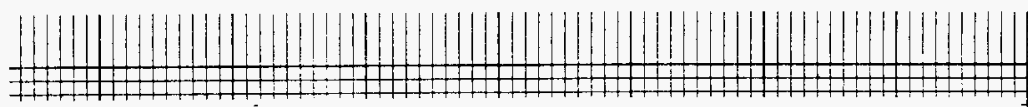

neannswiph

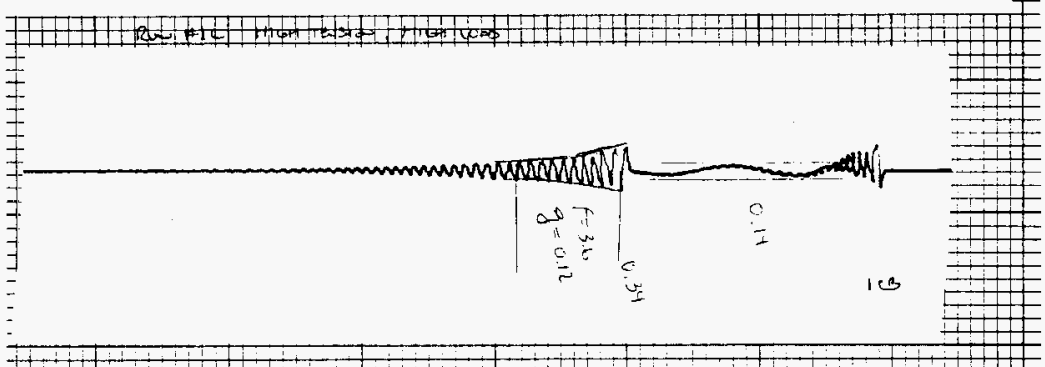

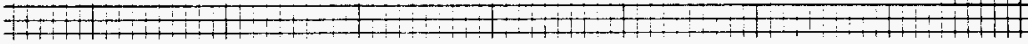
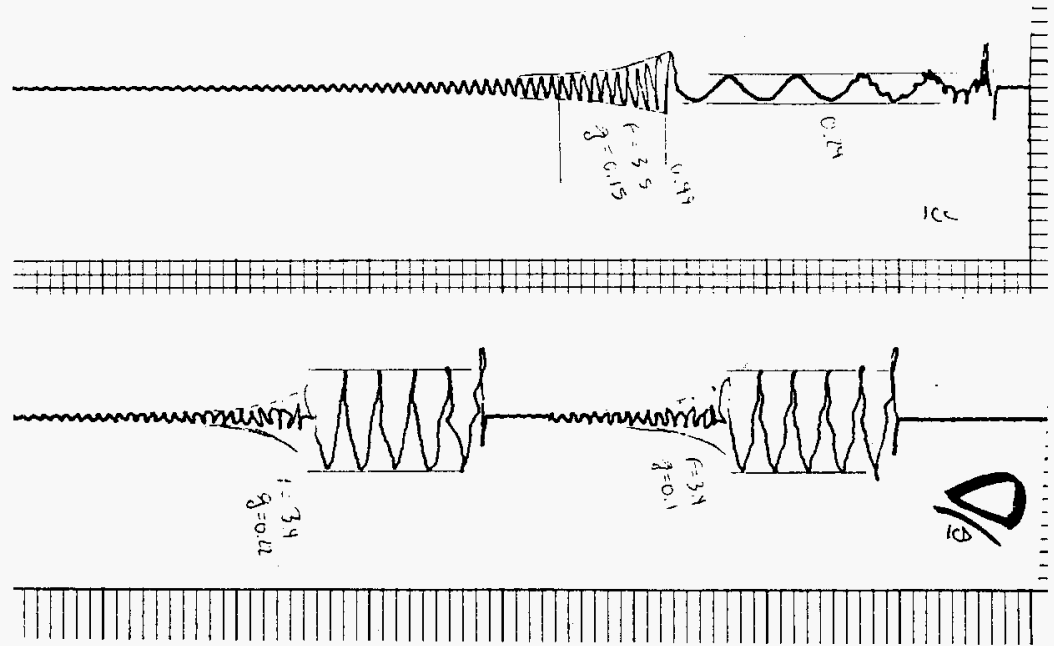


\section{WHC-SD-WM-TD-012, Rev 0}

\section{Strip charts from Run \#2}

Note: on some runs, it was difficult to mount the measurement apparatus such that the paper was parallel to the vibration. Either the mode is at an angle to the apparatus (as is shown here) or there is a change of mode as the vibration damps out -- thus making otherwise perfect alignment of measurement flawed.

Also, mounting for some modes allowed the pen to lift from the paper. In those cases, we switched to a pencil -- better contact with the paper, but a very light trace.

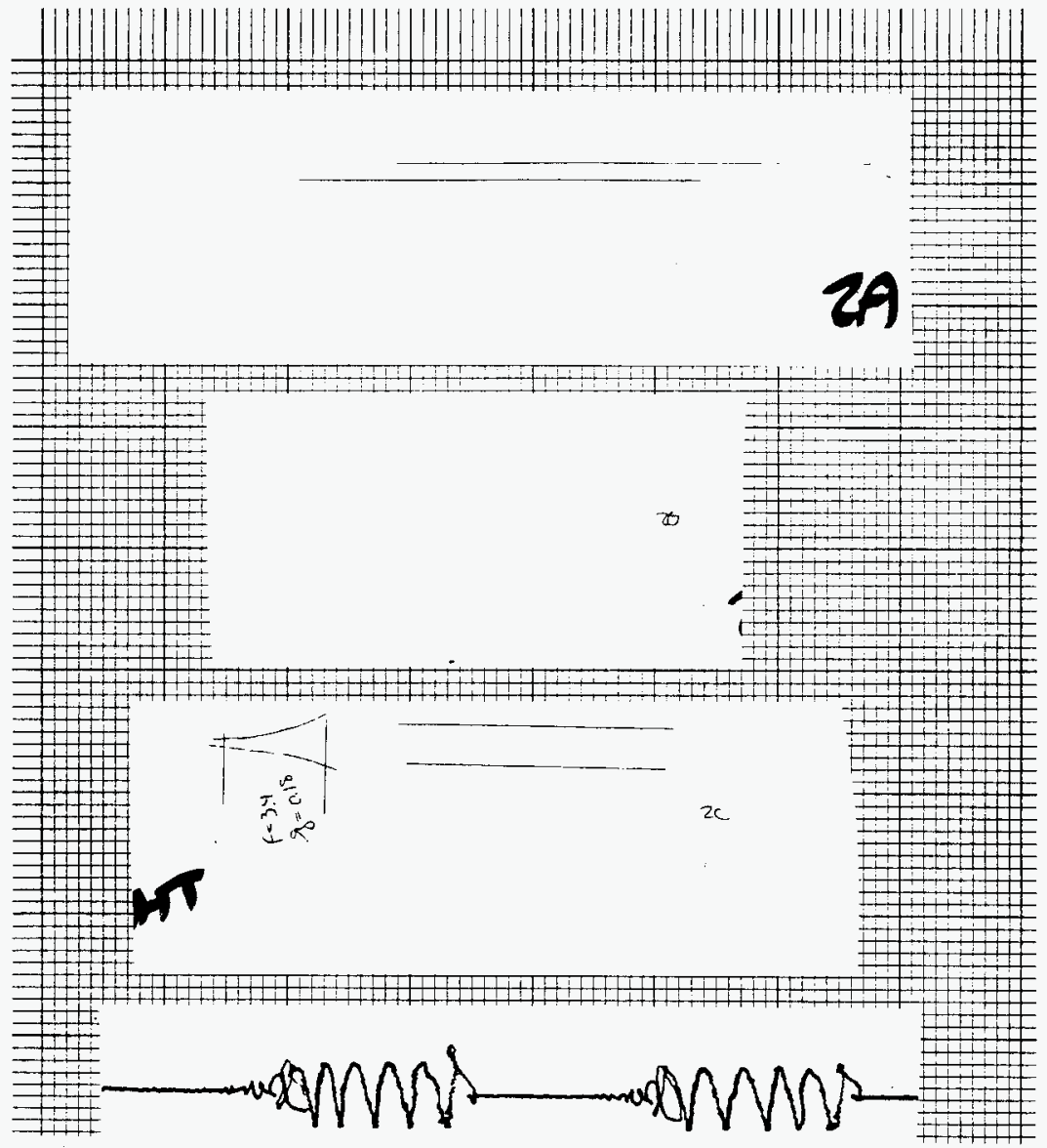


WHC-SD-WM-TD-012, Rev 0

Strip charts from Run \#3

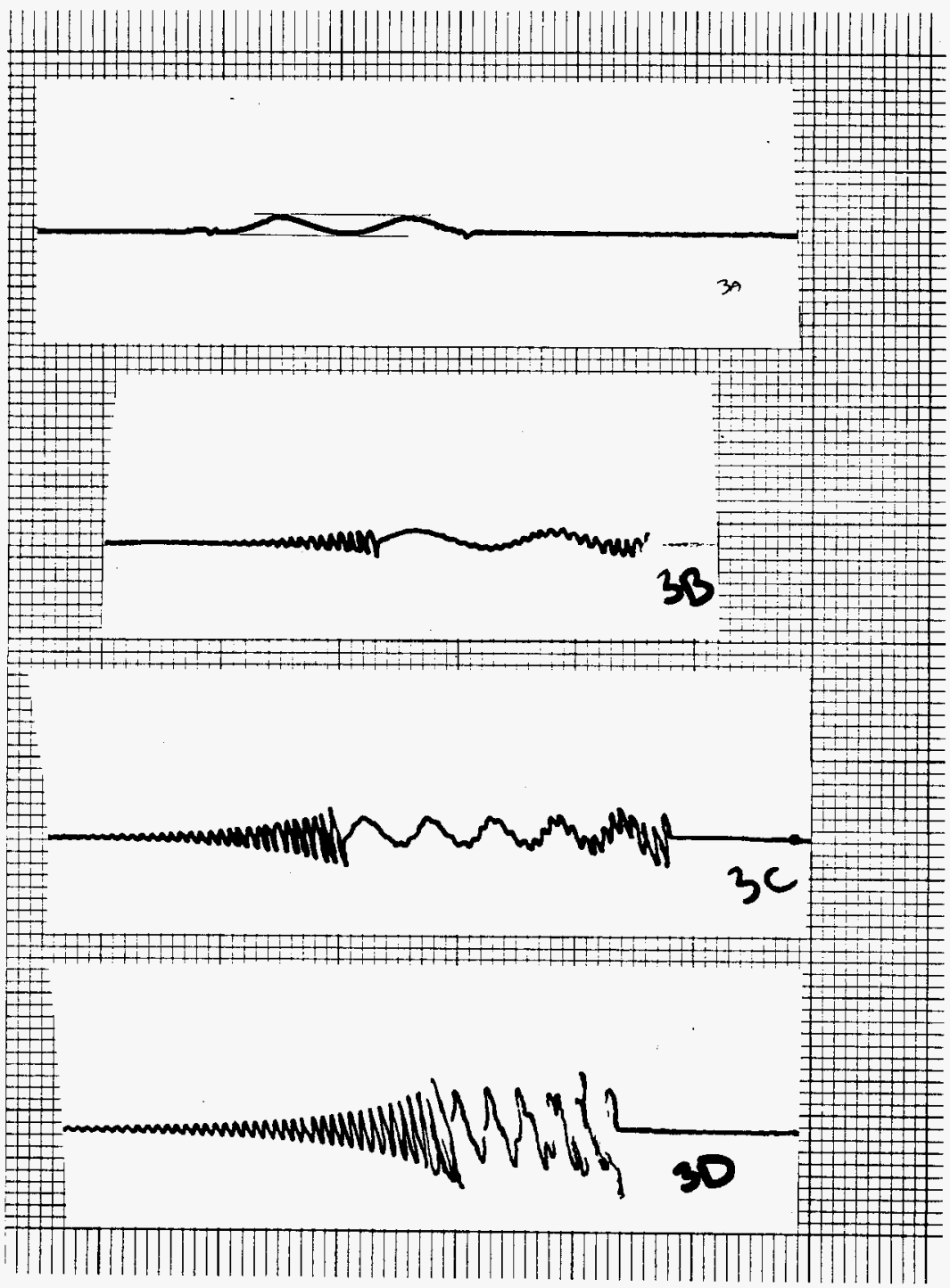




\section{Strip charts from Run \#4}

Note: as vibration amplitude became larger, modes that were difficult to measure were recorded with the paper held in a clipboard and supported by hand. This is reflected in 4D (next page) -- five repeats were used to give us confidence in the vibration amplitude.

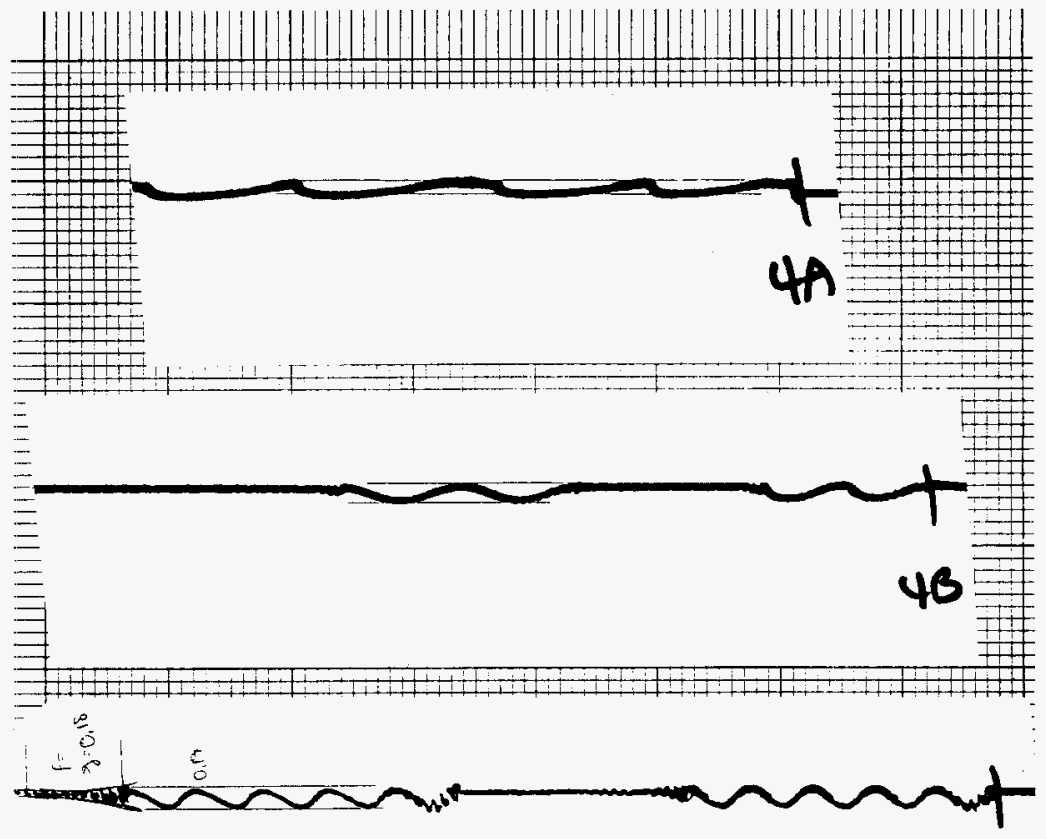

ye

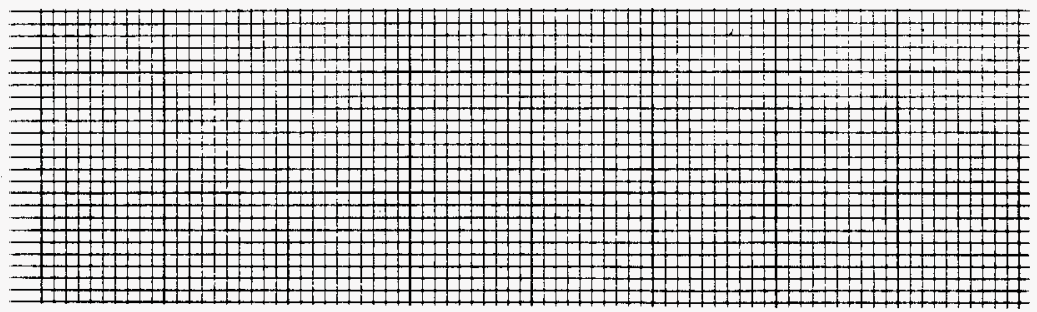


WHC-SD-WM-TD-012, Rev 0

Strip charts from Run \#4 (continued)

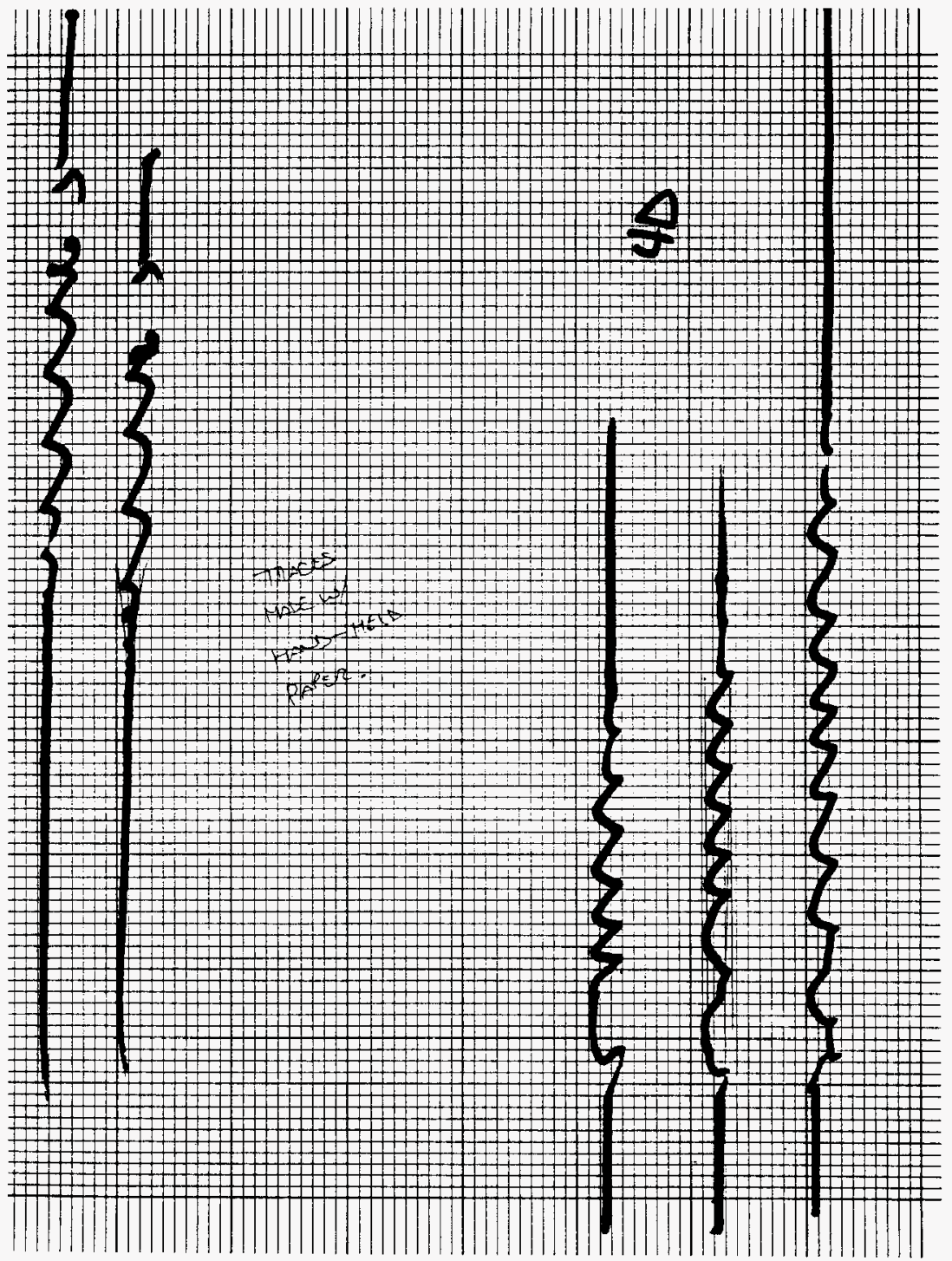




\section{Strip charts from Run \#5}

Note: when a mode had large amplitude and even the pencil could not record it along one dimension, we would take a repeat measurement and let the trace cover two dimensions, as is seen for 5D (next page).

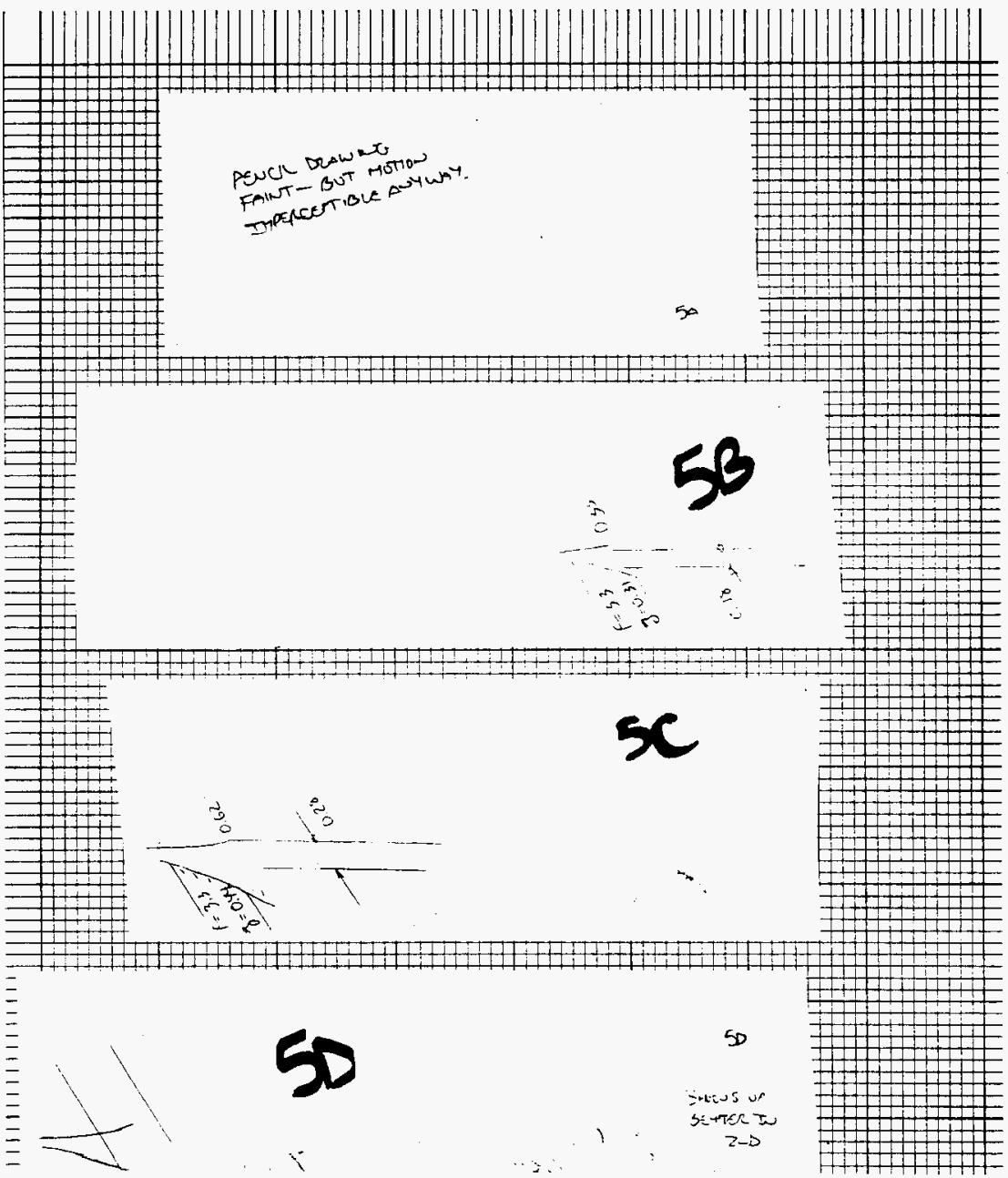


HHC-SD-WM-TD-012, Rev 0

Strip charts from Run \#5 (continued)

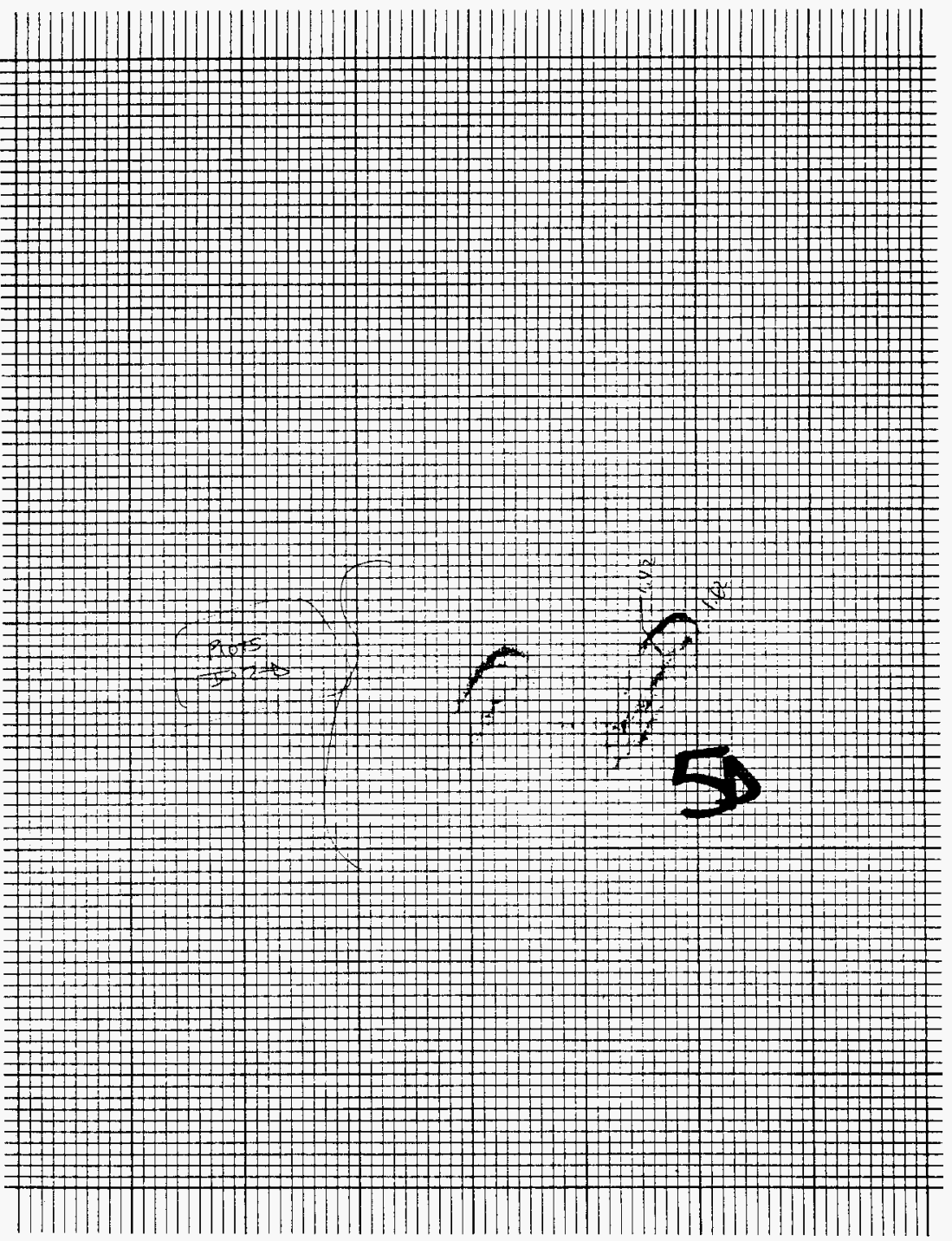


WHC-SD-WM-TD-012, Rev 0

Strip charts from Run \#6
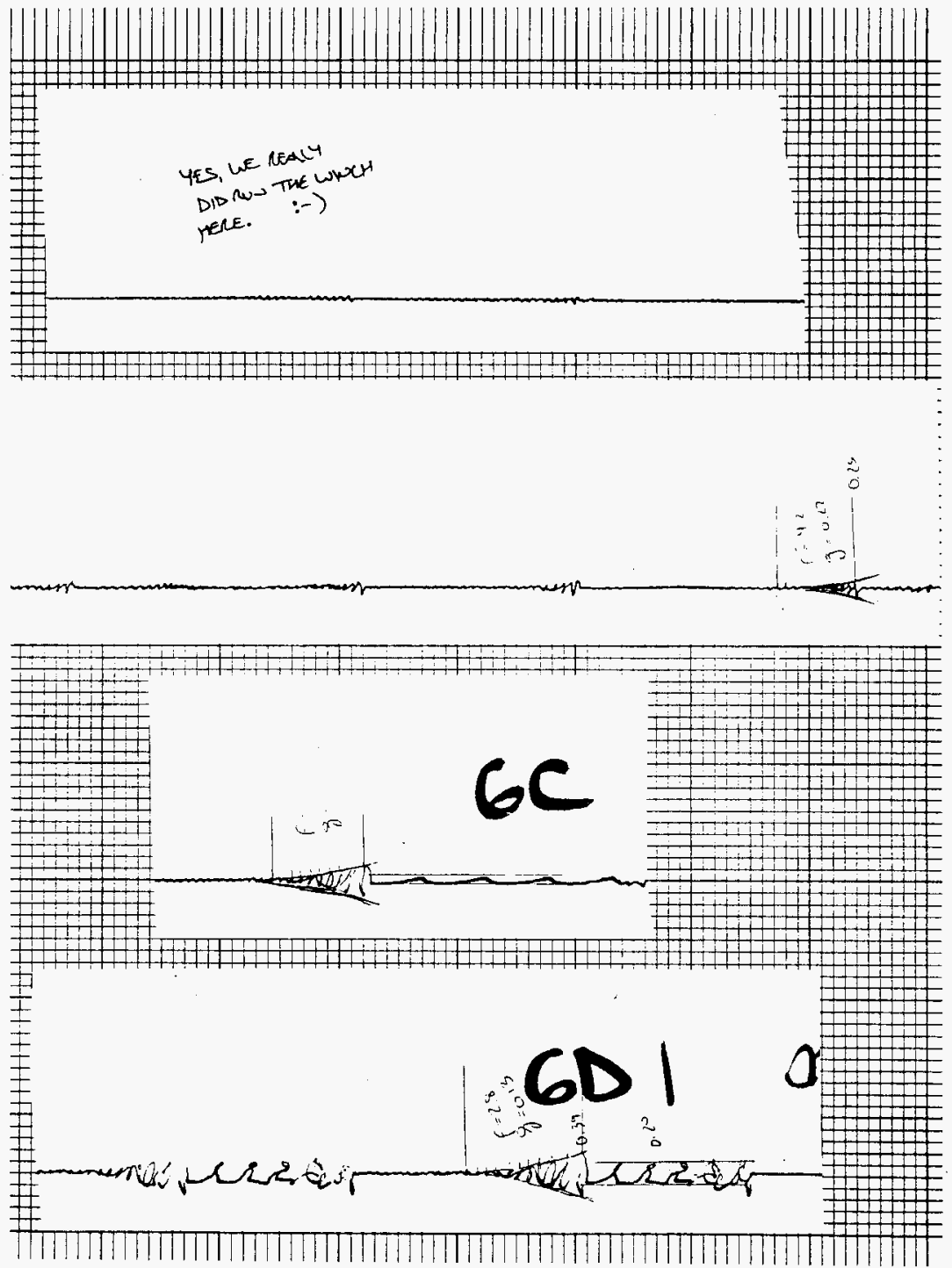
WHC-SD-WM-TD-012, Rev 0

Strip charts from Run \#7

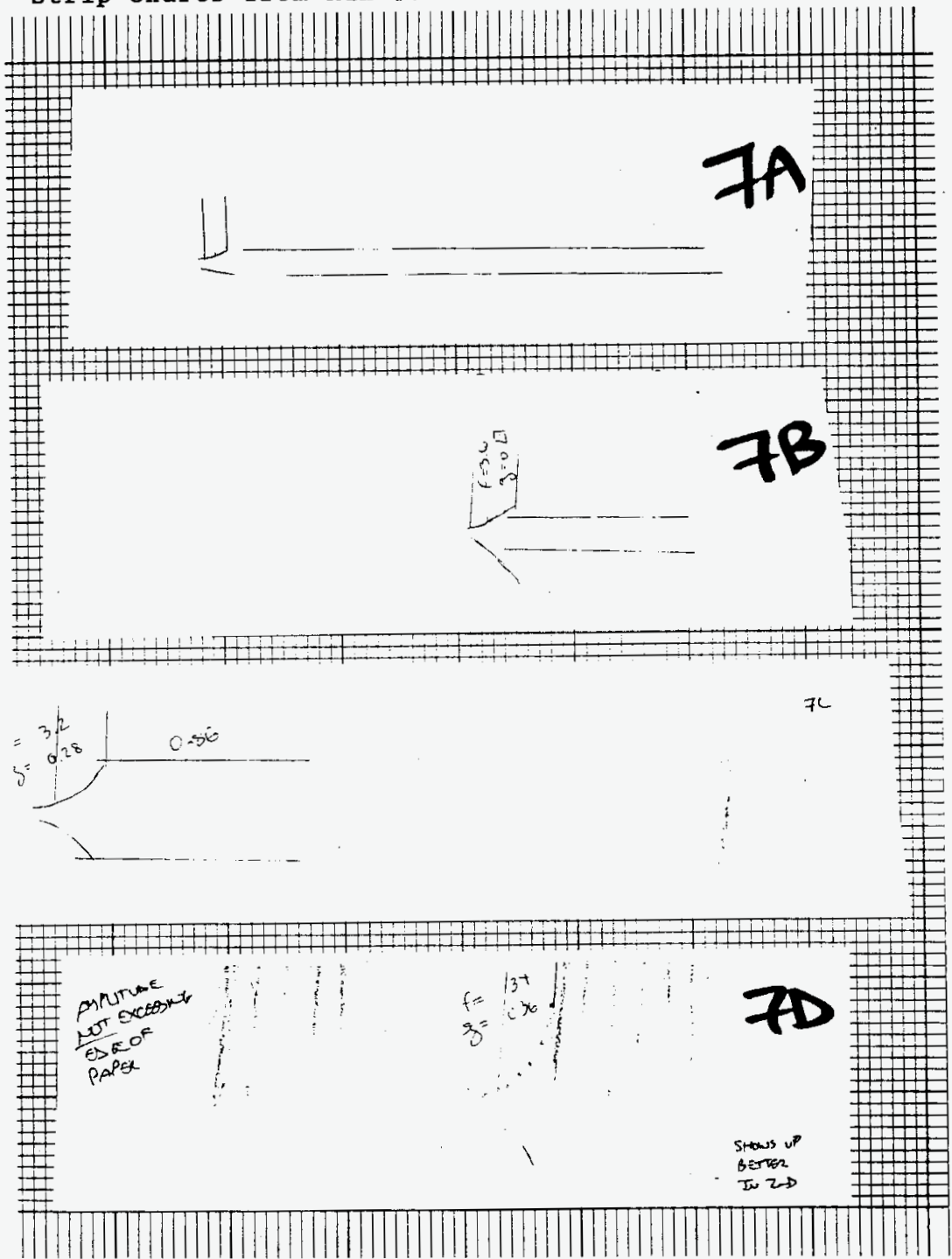


WHC-SD-WM-TD-012, Rev 0

Strip charts from Run \#7 (continued)

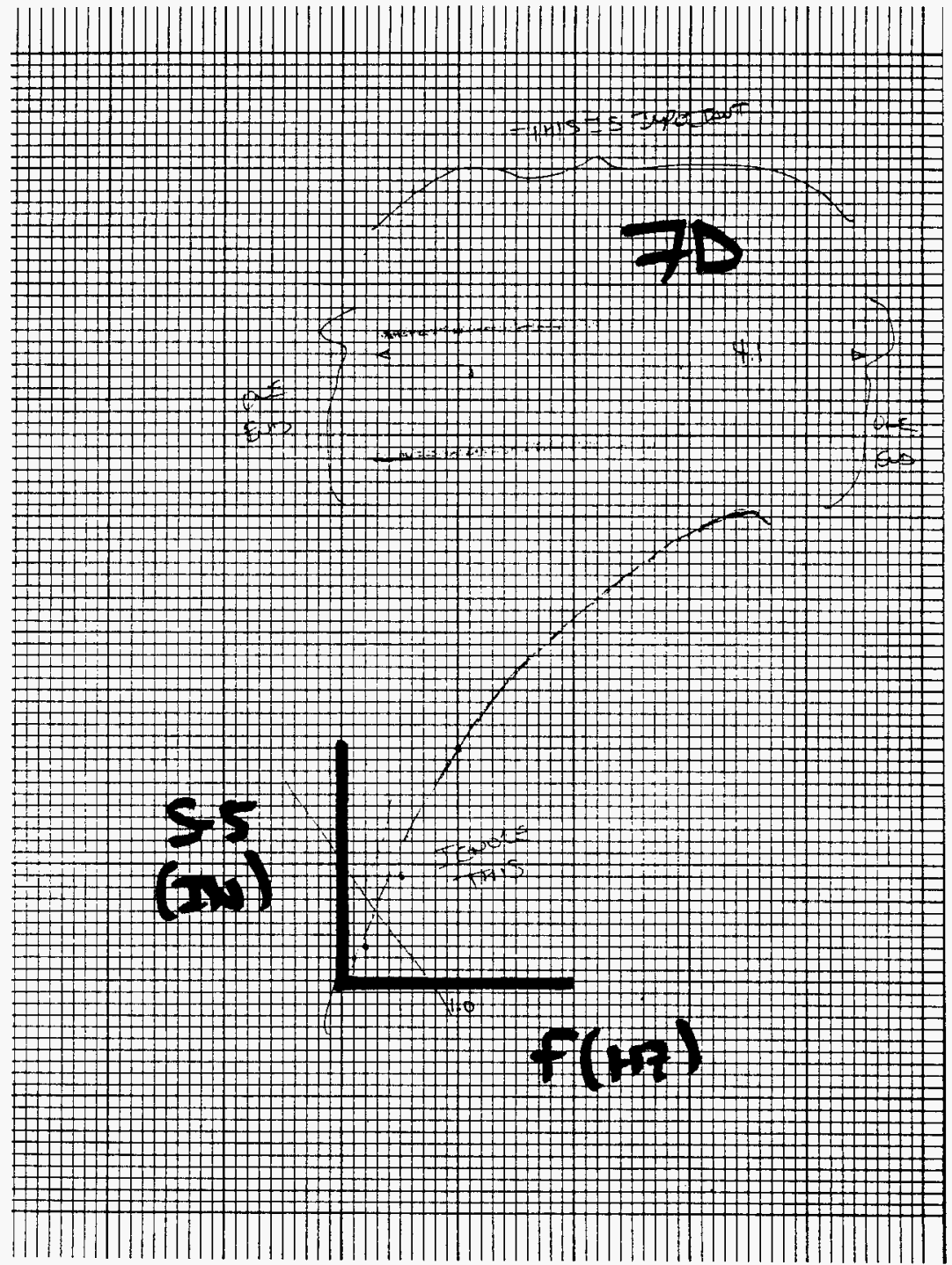

REST AYAILABLE COPY 
strip charts from Run \#8
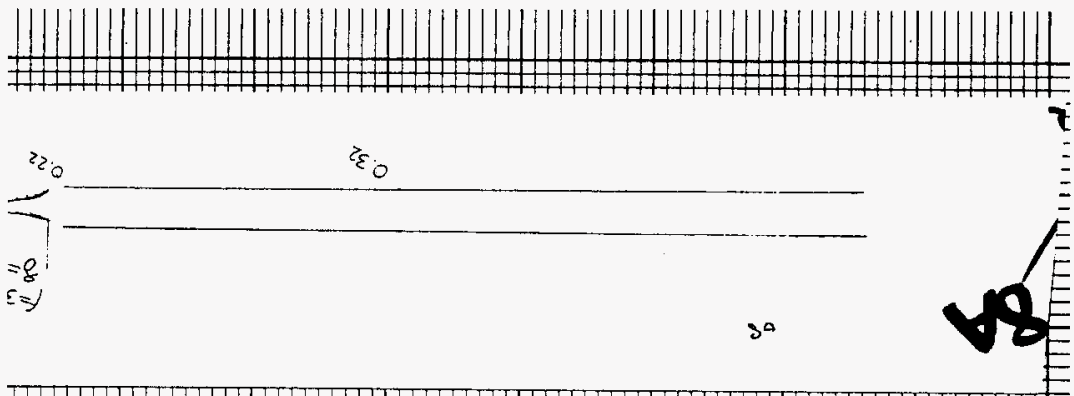

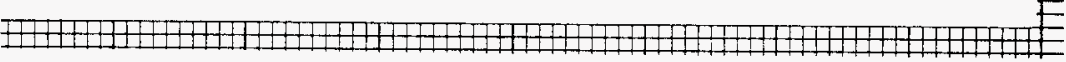
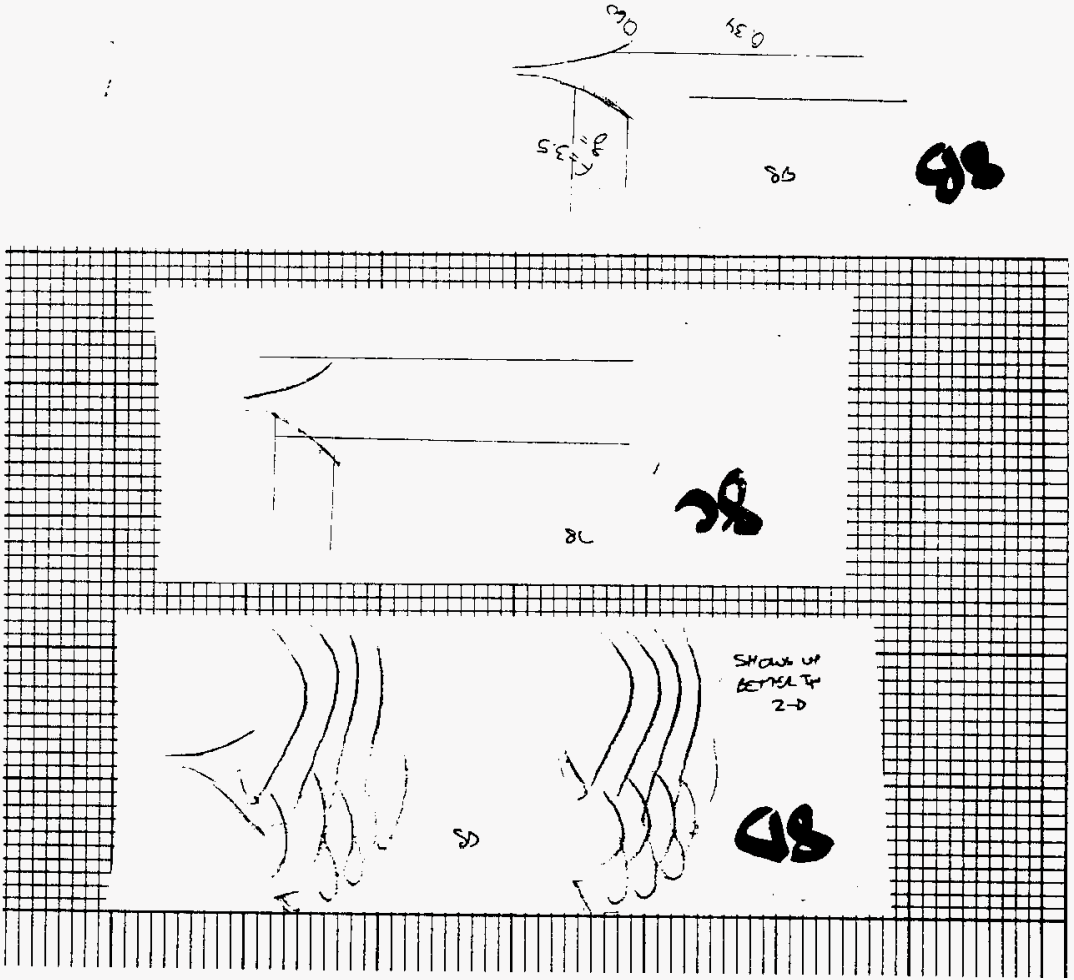
WHC-SD-WM-TD-012, Rev 0

Strip charts from Run \#8 (continued)

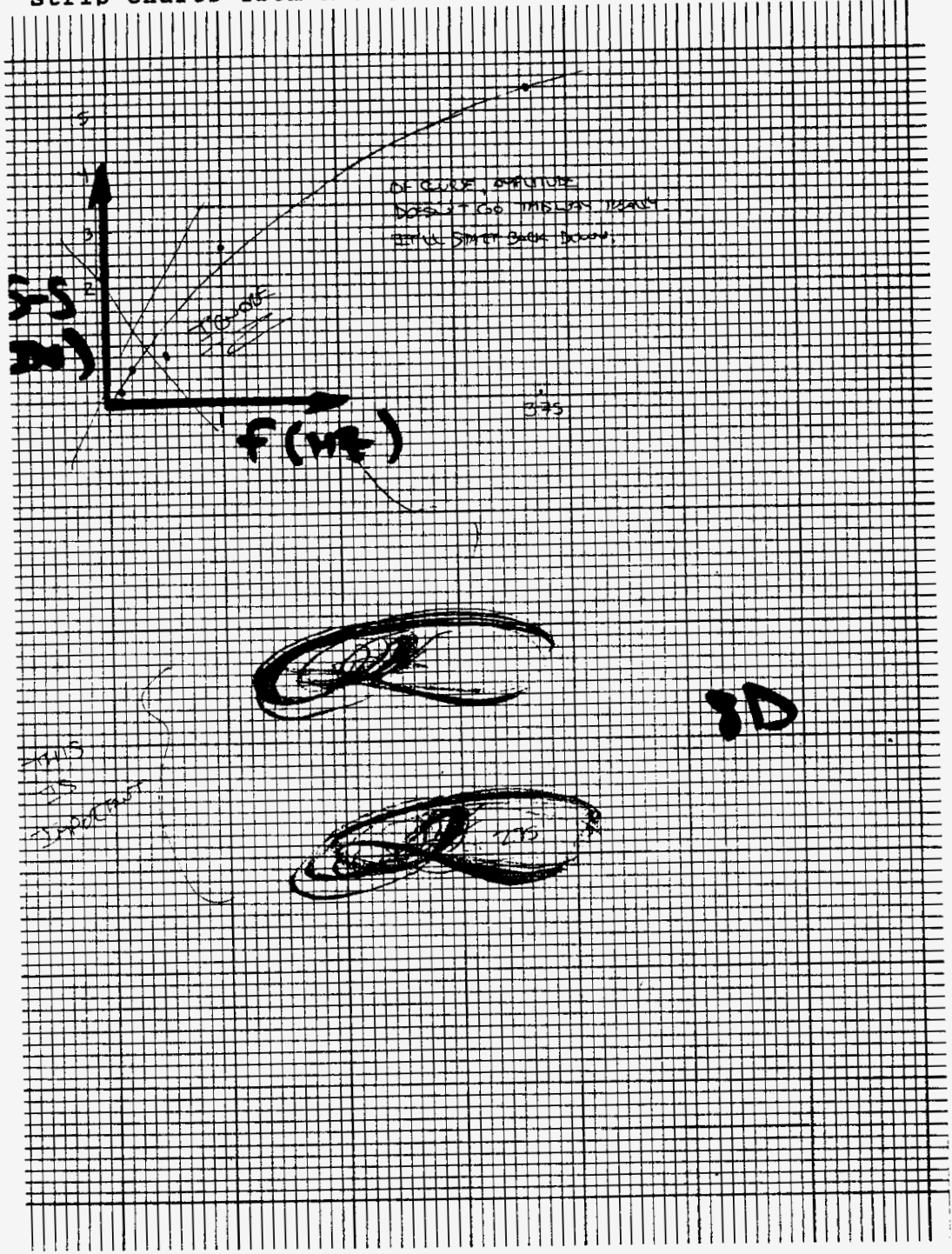

BEST AVAILABLE COPY 
Strip charts from Run \#9

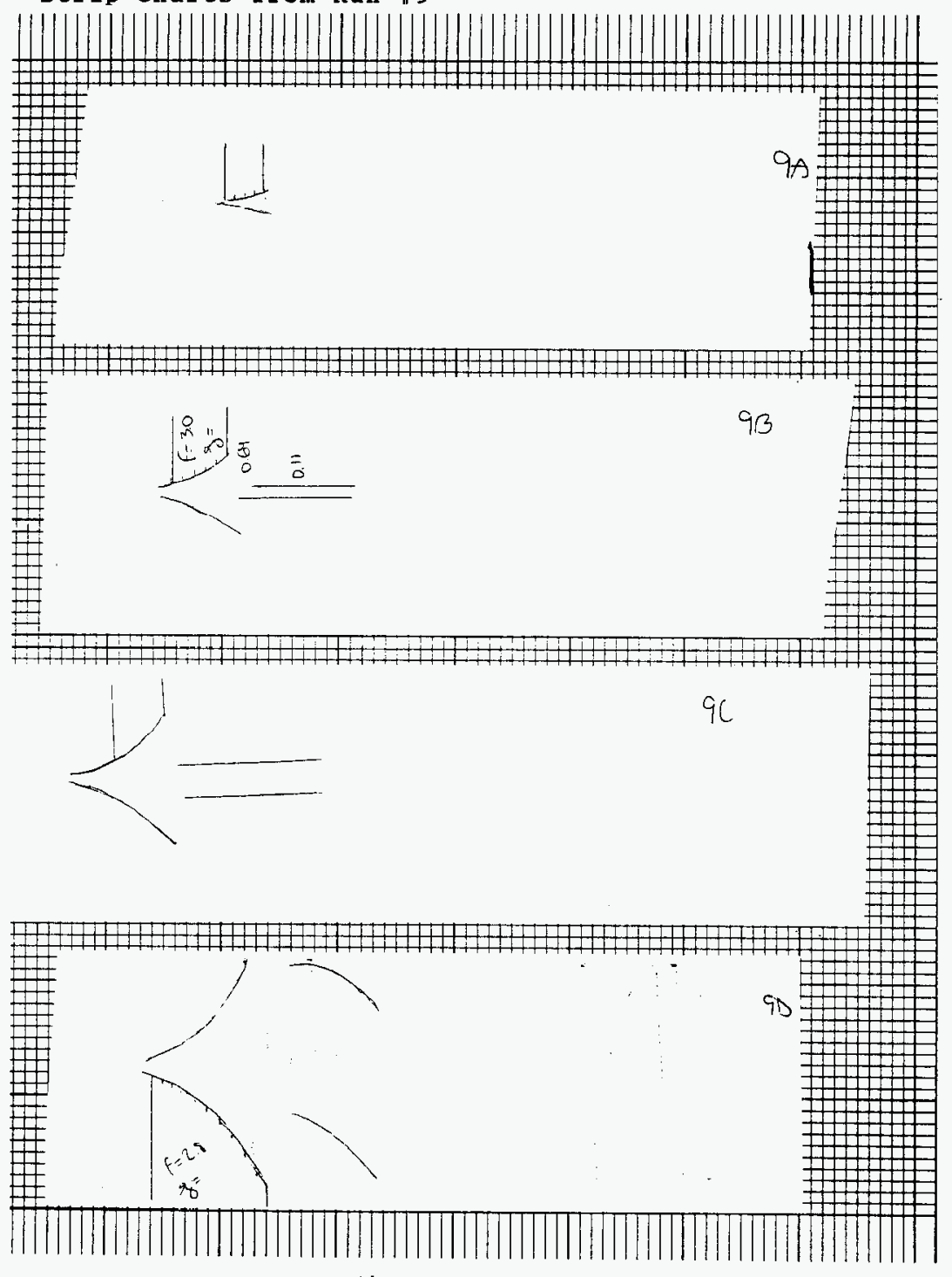




\section{Appendix D. Original Statement of Work}

\section{TEST PROCEDURE}

\subsection{Payload Accommodation}

Observations taken in tests under other sections (particularly sections 2.0 and 3.0 ) will enable us to determine the ability of a 30-foot EMMA to accommodate the expected waste-dislodging endeffector. In particular, what we are interested in is the separation between EMMA and end-effector resonance frequencies, and in the effect of the end-effector static load on cable tension. Testing in section 4.0 will result in an estimate of winch rate resolution -- something we can use to determine standoff capability.

Regular interaction with individuals with cognizance about the end-effector and its requirements will enable us to improve EMMA's accommodation capability.

\section{2 .0 Static Cable Tension Determination and Scale-up}

This series of tests will be performed with a scale dynamometer mounted alternately on the 12-0'clock proximal and 12-0'clock distal segment cables. These cables can be assumed for purposes of this test to undergo the largest static loads -- and the tests will be designed to ensure that these cables will be in full tension even though others may be relaxed. In the place of an end-effector will be a static load of 0,30 or $601 \mathrm{bf}$.

Two position cases will be considered:

Case \#1 -- proximal stage locked in horizontal position/distal stage rotated 90 degrees to vertical

Case \#2 -- proximal stage rotated 90 degrees to vertical/distal stage in-line

These position cases are probably the worst cases that will be faced by a two-stage EMMA.

The tests will be performed as follows:

- rotate stage being tested through 10-degree increments from neutral to final position, by pulling its 12-0'clock cable while leaving other cables relaxed

- measure tension in 12-0'clock cable using attached dynamometer

This method will give an estimate of maximum tension in a single cable, when that cable is bearing the entire load. 
Three static loads will be tested: 0,30 and 60 lbf, for a total of six tests, which will be repeated as necessary to ensure repeatability of result.

The measurements taken during these tests will enable us to estimate cable sizes necessary for fulfilling static load requirements in a 30-foot EMMA.

\subsection{Dynamic Cable Tension Requirements and scale-up}

This series of tests will be performed with a small rotating machine (characteristics TBD, although two are currently under consideration) holding an eccentric load (with weight and offset dependent on selection of rotating machine) attached to the end of the distal stage. Exact specs of the rotating machine are still under discussion, and should be resolved within a week. It is possible that weight and offset will be attractive experimental paraneters, as well as those described here.

Three position cases will be considered:

Case \#1 -- proximal stage rotated 90 degrees to vertical/distal stage in-line

Case \#2 -- proximal stage rotated 90 degrees horizontally/distal stage in-line

Case \#3 -- proximal stage rotated 90 degrees horizontally/distal stage rotated 90 degrees in the opposite direction ("scurve")

These position cases are probably the worst cases that will be faced by a two-stage EMMA, but others will be added if necessary.

Two mountings of dynamic load (both normal to axis of distal stage):

- Rotational axis in plane of manipulator

- Rotational axis normal to manipulator plane

These mountings will ensure end-effector displacement in two directions normal to the distal stage axis.

Several cable tensions in the neighborhood of the nominal value will be tested to examine flexibility.

Seven dynamic load frequencies to be examined:

$0.01,0.02,0.05,0.1,0.2,0.5,1 \mathrm{~Hz}$

These frequencies are chosen to be within the capability of whatever rotating machine is used in the tests; and to represent a selection of frequencies expected to be in the neighborhood of EMMA resonance. Other frequencies will be added if needed to allow for resolution in the frequency domain.

More than 100 runs are expected, in order to adequately cover all of these experimental parameters. Each will be carried out over 
sufficient duration to ensure steady-state oscillation. Each run will be repeated as necessary to ensure repeatability of result.

Quantities to be measured:

- maximum end-effector displacement

- maximum cable tension (12-0'clock)

Quantities to be determined:

- maximum bending moment in each stage

The quantities measured during these tests, and the maximum bending moments determined as a result, enable us to estimate cable pretension required for dynamic stability in a 30-foot EMMA.

\subsection{Kinematics and control}

This series of tests will be performed with electric winches engaged to the proximal stage. A preliminary joystick design will be prepared and tested with the six winches on the proximal stage.

- The joystick will be calibrated to ensure no winch motion with the joystick at the neutral position.

- The joystick will be used to rotate the proximal stage 90 degrees alternately along two different directions, with cable tension monitored in the shortest cable.

Six more winches will ultimately be added to the distal stage, and the joystick operation then retested on the distal stage.

These tests will enable us to determine a winch capacity and proximal cable conduit size and type suitable for a 30-foot EMMA.

\subsection{Pretension and stability}

The primary data necessary here is as follows:

- observations of proximal cable conduit behavior in other tests

- observations of winch suitability in tests performed in section 4.0

- observations of cable performance in tension in section 2.0 and 3.0 tests

Observations taken during the current testing will enable us to determine appropriate conduit size and stiffness, as well as an appropriate amount of free play for the conduit. We will also be able to assess placement of winches for best performance both of winches and cables in a 30-foot EMMA. 